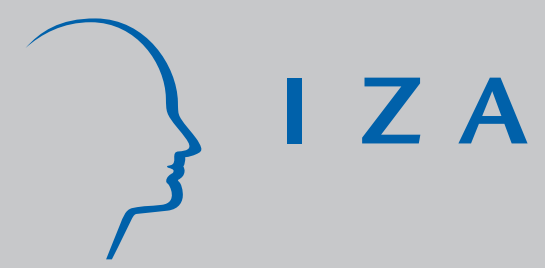

IZA DP No. 8850

The Pros and Cons of Sick Pay Schemes: A Method to Test for Contagious Presenteeism and Shirking Behavior

Stefan Pichler

Nicolas R. Ziebarth

February 2015

Forschungsinstitut zur Zukunft der Arbeit Institute for the Study of Labor 


\title{
The Pros and Cons of Sick Pay Schemes: A Method to Test for Contagious Presenteeism and Shirking Behavior
}

\author{
Stefan Pichler \\ ETH Zurich, KOF Swiss Economic Institute
}

Nicolas R. Ziebarth

Cornell University

and IZA

Discussion Paper No. 8850
February 2015

IZA

P.O. Box 7240

53072 Bonn

Germany

Phone: +49-228-3894-0

Fax: +49-228-3894-180

E-mail: iza@iza.org

Any opinions expressed here are those of the author(s) and not those of IZA. Research published in this series may include views on policy, but the institute itself takes no institutional policy positions. The IZA research network is committed to the IZA Guiding Principles of Research Integrity.

The Institute for the Study of Labor (IZA) in Bonn is a local and virtual international research center and a place of communication between science, politics and business. IZA is an independent nonprofit organization supported by Deutsche Post Foundation. The center is associated with the University of Bonn and offers a stimulating research environment through its international network, workshops and conferences, data service, project support, research visits and doctoral program. IZA engages in (i) original and internationally competitive research in all fields of labor economics, (ii) development of policy concepts, and (iii) dissemination of research results and concepts to the interested public.

IZA Discussion Papers often represent preliminary work and are circulated to encourage discussion. Citation of such a paper should account for its provisional character. A revised version may be available directly from the author. 


\section{ABSTRACT \\ The Pros and Cons of Sick Pay Schemes: A Method to Test for Contagious Presenteeism and Shirking Behavior}

This paper proposes a test for the existence and the degree of contagious presenteeism and negative externalities in sickness insurance schemes. First, we theoretically decompose moral hazard into shirking and contagious presenteeism behavior. Then we derive testable conditions for reduced shirking, increased presenteeism, and the level of overall moral hazard when benefits are cut. We implement the test empirically exploiting German sick pay reforms and administrative industry-level data on certified sick leave by diagnoses. The labor supply adjustment for contagious diseases is significantly smaller than for non-contagious diseases, providing evidence for contagious presenteeism and negative externalities which arise in form of infections.

JEL Classification: I12, I13, I18, J22, J28, J32

Keywords: sickness insurance, sick pay, presenteeism, contagious diseases, infections, negative externalities, shirking

Corresponding author:

Nicolas R. Ziebarth

Cornell University

Department of Policy Analysis and Management (PAM)

106 Martha Van Rensselaer Hall

Ithaca, NY 14850

USA

E-mail: nrz2@cornell.edu

\footnotetext{
"We would like to thank Davide Dragone, Laszlo Goerke, Martin Karlsson, Sean Nicholson, and Sarah Prenovitz for excellent comments and suggestions. We also thank participants in research seminars at Cornell University (PAM), the University of Linz (Economics Department), the Berlin Network of Labor Market Researchers (BeNA), and at the Centre for Research in Active Labour Market Policy Effects (CAFE) Workshop at Aarhus University for their helpful comments and suggestions. In particular we would like to thank Eric Maroney and Philip Susser for excellence in editing this paper. We or our employers have no relevant or material financial interests that relate to the research described in this paper. We take responsibility for all remaining errors in and shortcomings of the paper.
} 
"Send me a bill that gives every worker in America the opportunity to earn seven days of paid sick leave. It's the right thing to do. It's the right thing to do."

"I think the Republicans would be smart to get behind it."

Bill O'Reilly

in The O’Reilly Factor - Fox News (January 21, 2015)

\section{Introduction}

One major economic justification for publicly provided access to paid sick leave is "presenteeism" and negative externalities in case of contagious diseases. When workers lack access to paid sick leave, they may go to work despite being sick. This situation is referred to as "presenteeism." Particularly in professions with direct customer contact, presenteeism in case of contagious diseases unambiguously leads to negative externalities and infection spillovers to co-workers and customers. Given the low vaccination rates of around $40 \%$ in the US and 10\% to 30\% in the EU (Blank et al., 2009; Centers for Disease Control and Prevention, 2014a), workplace presenteeism is one important channel through which infectious diseases spread. After the first occurrence of flu sickness symptoms, humans are contagious for 5 to 7 days (Centers for Disease Control and Prevention, 2014b). Over-the-counter (OTC) drugs that suppress symptoms but not contagiousness promote the spread of disease in cases of presenteeism and non-insured workplace absenteeism (Earn et al., 2014). Worldwide, seasonal influenza epidemics alone lead to 3 to 5 million severe illnesses and an estimated 250,000 to 500,000 deaths; in the US, flu-associated annual deaths range from 3,000 to 49,000 (World Health Organization, 2014: Centers for Disease Control and Prevention, 2014b).

Opponents of universal paid sick leave point to the fact that such social insurance systems would encourage shirking behavior and reduce labor supply. Moreover, forcing employers to provide sick pay via mandates or new taxes would dampen job creation and hurt employment. A last argument against state regulated paid sick leave is that the private market would ensure that employers voluntarily provide such fringe benefits if such fringe benefits were truly optimal. 
Historically, paid sick leave was actually one of the first social insurance pillars worldwide: This policy was included in the first federal health insurance legislation. Under Otto van Bismarck, the Sickness Insurance Law of 1883 introduced social health insurance which included 13(!) weeks of paid sick leave along with coverage for medical bills. The costs associated with paid sick leave initially made up more than half of all program costs, given the limited availability of expensive medical treatments in the $19^{\text {th }}$ century (Busse and Riesberg, 2004). Other European countries followed quickly and, today, virtually every European country has some form of universal access to paid sick leave-with varying degrees of generosity. The US is the only industrialized country worldwide without universal access to paid sick leave (Heymann et al., 2009). 49\% of American employees have no access to sick pay, particularly low-income and service sector workers (Lovell, 2003; Boots et al. 2009). However, in the US, support for paid sick leave has grown substantially in the last decade: Several sick leave schemes were implemented in Seattle, Washington D.C., San Francisco, and most recently New York City. Connecticut was the first state to introduce a sick leave scheme (for service sector workers in non-small businesses) in 2012. Reintroduced in Congress in March 2013, the Healthy Families Act foresees the introduction of universal paid sick leave for up to seven days per employee and year at the federal level .

As outlined above, the economic legitimation for paid sick leave hinges crucially on the existence of negative externalities and presenteeism with regard to contagious diseases. However, empirically proving the existence of presenteeism in cases of contagious diseases is extremely difficult. Several empirical papers have evaluated the causal effects of cuts in sick pay, and found that employees adjust their labor supply in response to such cuts (Johansson and Palme, 1996, 2005; Ziebarth and Karlsson, 2010; De Paola et al., 2014; Ziebarth and Karlsson, 2014; Dale-Olsen, 2014; Fevang et al., 2014).1. Traditionally, behavioral adjustments to varying levels of insurance generosity is labeled moral hazard in economics (Pauly, 1974, 1983; Arnott and Stiglitz, 1991; Nyman, 1999; Newhouse, 2006; Felder, 2008;

\footnotetext{
${ }^{1}$ Other papers in the literature on sickness absence looked at and decomposed general determinants (Barmby et al. 1994; Markussen et al., 2011), investigated the impact of probation periods (Riphahn, 2004: Ichino and Riphahn. 2005), culture (Ichino and Maggi, 2000), gender (Ichino and Moretti, 2009), income taxes (Dale-Olsen, 2013), and unemployment (Askildsen et al., 2005; Nordberg and Røed. 2009:|Pichler, 2014). There is also research on the impact of sickness on earnings (Sandy and Elliott. 2005:|Markussen.,2012).
} 
Bhattacharya and Packalen, 2012). However, in case of sick leave, being able to disentangle shirking behavior from presenteeism is crucial in order to derive valid policy conclusions.

The main objective of this paper is to develop an approach to test for the existence of shirking, contagious presenteeism and associated negative externalities in workplace settings with sickness insurance coverage. This paper is the first in the economic literature to define and test for the existence of contagious presenteeism. The first part of the paper develops an economic model that decomposes moral hazard into shirking and contagious presenteeism. According to this theoretical framework, the negative externalities can be quantified by assessing changes in infections after changes in sick pay. The model predicts that changes in sick pay induce changes in the two undesired behaviors that work in opposite directions: shirking and contagious presenteeism. We explicitly refrain from a normative welfare analysis which would require to weight these two phenomena, depending on societal preferences. We rather provide a positive analysis and the first approach to theoretically define and empirically measure these countervailing effects.

The second part of the paper exploits two German policy reforms which varied the level of sick pay. Using administrative data aggregated at the industry level and differences in industry-specific sick pay regulations, we show that sick pay cuts from 100 to $80 \%$ of foregone wages reduced the sickness rate by about $20 \%$ on average. This is in line with the standard predictions of our model and the previous literature (Johansson and Palme, 1996, 2005. Ziebarth and Karlsson, 2010; Puhani and Sonderhof, 2010; De Paola et al., 2014; Ziebarth and Karlsson, 2014: Fevang et al., 2014). Next, and more importantly, we are able to analyze the labor supply effects separately by certified disease categories. In line with the theoretical model implications, we find disproportionately large labor supply adjustments for musculoskeletal diseases. Meanwhile, the sickness rate of infectious diseases did not decrease by the same proportions. This difference can be explained by additional infections that increase sick leave rates and compensate for reductions due to lower sick pay. Thus, when mandated sick pay is lowered, policymakers have to consider the trade-off between (i) the short-run effect of a reduction in shirking vs. (ii) an increase in contagious presenteeism leading to (iii) a higher infection rate and more relapses in the medium-run. 
Obviously, this paper is close in spirit to papers that estimate causal labor supply effects of changes in sick pay levels (e.g. Johansson and Palme, 1996, 2002, 2005; Ziebarth, 2013; Ziebarth and Karlsson, 2010, 2014). In particular, it extends the small economic literature on presenteeism at the workplace (Aronsson et al., 2000; Chatterji and Tilley, 2002, Brown and Sessions, 2004; Pauly et al., 2008; Barmby and Larguem, 2009; Markussen et al., 2012;:Pichler. 2014). With one exception, none of the empirical studies on presenteeism just cited identifies or intends to identify causal effects of sick leave schemes on presenteeism. Markussen et al. (2012) studies the impact of partial absence certificates on presenteeism but defines presenteeism very broadly - as a reduction in sick leave when activation requirements become tighter. Pauly et al. (2008) ask 800 US managers about their view on employee presenteeism with (a) chronic and (b) acute diseases-with respect to firm costs and separately by occupation and type of work. Pichler (2014) provides evidence for the hypothesis that presenteeism is procyclical due to a higher workload during economic booms. A paper that is similar to ours is Barmby and Larguem (2009). They exploit daily absence data from a single employer and estimate absence determinants as well as transmission rates of contagious diseases, linking the estimation approach nicely to an economic model of absence behavior.

Finally, this paper also adds to the literature on the determinants and consequences of epidemics and vaccinations (cf. Mullahy, 1999; Bruine de Bruin et al., 2011; Uscher-Pines et al., 2011). For example, Maurer (2009) models supply and demand side factors of influenza immunization, whereas Karlsson et al. (2014) empirically assess the impact of the 1918 Spanish Flu on economic performance in Sweden.

The first part of the paper theoretically defines and decomposes moral hazard into shirking and contagious presenteeism behavior in case of sick leave. The empirical application of our proposed test exploits variation in federal employer mandates in combination with industry-specific collective bargaining regulations. Note that the theory and empirical sections do not hinge on whether the sick pay scheme is mandated by the government or not, and this paper's main objective is not to study the welfare effects of employer mandates, but rather to generally decompose moral hazard in the context of employer-provided sick pay schemes. Although related and sometimes combined in laws, sick pay schemes differ 
crucially from maternity leave schemes due to (i) the negative externalities induced by contagious presenteeism in combination with (ii) information asymmetries between employers and employees about the type and extend of the employee's disease. Several important papers study the labor market effects of mandated maternity and family leave (Gruber, 1994; Ruhm, 1998; Waldfogel, 1998; Rossin-Slater et al., 2013; Thomas, 2015).

The next section discusses our economic model and derives testable conditions under presenteeism and contagious diseases. Section 3 explains the German sick leave system and the policy reforms. Section 4 discusses the data, the variables generated, and the empirical approach. In the final two sections, we present the empirical results and conclude.

\section{A Method to Identify Contagious Presenteeism and Negative Externalities}

\subsection{Modeling Shirking and Presenteeism}

We extend and build upon a mix of standard leisure-work models to theoretically study the absence behavior of workers (cf. Brown, 1994; Barmby et al., 1994; Brown and Sessions, 1996). While there might be additional arguments for or against the provision of sick pay, our theoretical model below focuses on employee shirking and presenteeism behavior, the associated infections, and the consequential trade-off..$^{2}$ Since we construct a model of individual behavior we omit the $i$ subscript in order to simplify notation. We specify the individual utility function as:

$$
u_{t}=\left(1-\sigma_{t}\right) c_{t}+\sigma_{t} l_{t}, \quad \text { with } \sigma_{t} \in[0,1],
$$

\footnotetext{
${ }^{2}$ In particular, we abstain from modeling the employer's side and effects on the firm level. This could include employer signaling (or adverse selection) effects, peer effects, or discrimination against identifiable unhealthy workers (e.g. obese workers). We also abstain from analyzing general equilibrium labor market effects.
} 
where $u_{t}$ represents the utility of a worker at time $t, c_{t}$ stands for consumption and $l_{t}$ for leisure. The current sickness level is $\sigma_{t}$, with larger values of $\sigma_{t}$ representing a higher degree of sickness. This parameter is private information of the worker and unknown by the firm.

In time periods with high levels of $\sigma_{t}$, i.e., when the worker is very sick, utility is mostly drawn from leisure or recuperation time rather than consumption. On the other hand, if the sickness level is relatively low, the worker attaches more weight to consumption as opposed to leisure 3

With $h$ defining hours of contracted work, $T$ the total amount of time available-and assuming that workers are not saving, but consuming their entire income from work $w_{t}$ or sick pay $s_{t}$-one can write the indifference condition between working and (sickness) absence formally as:

$$
\left(1-\sigma_{t}\right) s_{t}+\sigma_{t} T=\left(1-\sigma_{t}\right) w_{t}+\sigma_{t}(T-h)
$$

In most countries sick pay is not a flat monetary amount but rather a replacement rate of the current wage. Hence we substitute sick pay with $s_{t}=\alpha_{t} w_{t}$ in the equation above (with $\left.\alpha_{t} \in[0,1]\right) 4^{4}$ Moreover, workers are paid based on their average productivity and, approximating reality, we assume rigid wages and thus a time invariant wage level $w$. We can then calculate the indifference point $\sigma^{*}\left(\alpha_{t}\right)$ for a given replacement rate $\alpha_{t}$ :

$$
\sigma^{*}\left(\alpha_{t}\right)=\frac{\left(1-\alpha_{t}\right) w}{\left(1-\alpha_{t}\right) w+h}
$$

Hence if $\sigma_{t}>\sigma^{*}\left(\alpha_{t}\right)$ workers will be absent, while they will be present if $\sigma_{t}<\sigma^{*}\left(\alpha_{t}\right)$. The latter can be thought of the "normal" state under which the great majority, 80 to $90 \%$ of all workers, fall every day. The value of $\sigma^{*}\left(\alpha_{t}\right)$ where workers are indifferent solely depends on

\footnotetext{
${ }^{3}$ While our model focuses on sickness and sickness absence, in principle a high $\sigma_{t}$ only indicates a temporary preference for leisure. This might not necessarily be related to sickness and associated recuperation time, but also to other factors, such as sickness of family members and recreational activities.

${ }^{4}$ Notice that the wage may also include non-monetary benefits, such as more job security. For instance Scoppa and Vuri (2014) find that workers who are absent more frequently face higher risks of dismissal. Thus even in countries with nominally full replacement, in our model, this might translate to a replacement rate smaller than one due to future income opportunities and other costs and benefits.
} 
(i) the amount of money workers lose while on sick leave, $\left(1-\alpha_{t}\right) w$, and (ii) the contracted amount of working hours $h$.

\section{Introducing Two Types of Diseases and Negative Externalities Due to Contagious Pre- senteeism}

Next, let us assume that two types of (mutually exclusive) diseases exist: (i) contagious diseases denoted by subscript $c$, e.g., flus and (ii) non-contagious diseases denoted by subscript $n$, e.g. back pain $5^{5}$ More precisely, we assume that at every point in time the worker is either healthy $\sigma_{t}=0$ with probability $1-q-p_{t}, \sqrt{6}$ sick due to a non-contagious disease $\sigma_{t}=\sigma_{n t}$ with probability $q$ or sick due to a contagious disease $\sigma_{t}=\sigma_{c t}$ with probability $p_{t}$. In the latter two cases the actual size of the disutility created by the sickness $\sigma_{t}$ is determined by the density function $f(\sigma)$. Thus while the level of $\sigma_{t}$ determines the decision of the worker to stay at home or not, we now add an additional characteristic to this variable which determines whether the disease is contagious or not. Moreover, we assume that conditional on being sick $(\sigma>0)$ the probabilities of disease types $\left(p_{t}\right.$ and $\left.q\right)$ are independent of the density of the sickness level $f(\sigma)$.

As already mentioned, both the severity of the disease and the worker's "disease type" drawn by the worker is private information and thus we abstract away from situations when an employer detects a worker with a contagious disease at work and sends the worker home in order to avoid infections. This private information assumption seems reasonable given that disease type and contagiousness are mostly unobservable and subject to very incomplete monitoring. In that context, consider that most infectious diseases are contagious for days before symptoms are clearly observable. The availability and popularity of OTC drugs suppressing disease symptoms reinforce the unobservability assumption (Earn et al., 2014).

Finally, the probability of being affected by a contagious disease $p_{t}$ changes over time depending on infections in the previous period, as outlined in detail below. The probability

\footnotetext{
${ }^{5}$ In principle non-contagious diseases represent a special case of contagious diseases, where infections are equal to zero. Moreover, (diseases with) relapses can also be considered as a special case of contagious diseases, where the level of contagiousness is fairly low, as individuals "infect" only themselves.

${ }^{6}$ We assume that these probabilities are the same for all individuals considered.
} 
for drawing a non-contagious diseases $q$ on the other hand is not time varying but fixed and thus we omit the time index $t .7$

Given $\sigma^{*}\left(\alpha_{t}\right)$ and assuming a worker population of size 1, we can now define the sick leave rate $A_{t}$ as the share of individuals absent from work:

$$
A_{t}=A_{c t}+A_{n t}=\left(p_{t}+q\right) \int_{\sigma^{*}\left(\alpha_{t}\right)}^{1} f(\sigma) d \sigma
$$

similarly, the share of workers present is given by

$$
P_{t}=\left(1-p_{t}-q\right)+\left(p_{t}+q\right) \int_{0}^{\sigma^{*}\left(\alpha_{t}\right)} f(\sigma) d \sigma
$$

Given the replacement rate $\alpha_{t}$, a share of workers

$$
\pi_{t}\left(\alpha_{t}\right)=p_{t} \int_{0}^{\sigma^{*}\left(\alpha_{t}\right)} f(\sigma) d \sigma
$$

is contagious but present at work. We define $\pi_{t}\left(\alpha_{t}\right)$ as contagious presenteeism. One economic purpose of providing paid sick leave is to provide financial incentives such that infections caused by contagious presenteeism are minimized.

As seen, the share of workers with contagious presenteeism behavior who transmit diseases to their co-workers and to customers equals $\pi_{t}\left(\alpha_{t}\right)$. Following a standard SIS (susceptibleinfected-susceptible) endemic model ${ }^{8}$ the transmission of diseases at the workplace depends on three factors: (a) the share of contagious workers working (the infected) $\pi_{t}$, (b) the share of non-contagious individuals present at work (the susceptibles) $S_{t}=\left(1-p_{t}-\right.$ $q)+q \int_{0}^{\sigma^{*}\left(\alpha_{t}\right)} f(\sigma) d \sigma$, and (c) the transmission rate of the disease which we denote with $r .9$ Therefore the probability of catching a contagious disease is an increasing function of these

\footnotetext{
${ }^{7}$ Notice that we abstract from any competing risks since an increase in contagious diseases does not affect the probability of having a non-contagious diseases. While substitution might take place, we assume it is of a small enough margin not to be considered here.

${ }^{8}$ The SIS model is the classic framework for mathematically analyzing contagious diseases and was first discussed in the medical literature by Ross (1916) and Kermack and McKendrick (1927).

${ }^{9}$ It is outside the scope of this paper to model the transmission rate of contagious diseases explicitly (cf. Philipson, 2000: Barmby and Larguem, 2009, Pichler, 2014).
} 
three elements $p_{t}\left(\pi_{t}, S_{t}, r\right)$. Thus contagious workers who show up at the workplace trigger the negative externalities that sick pay schemes intend to minimize.

\section{Severely Sick Workers and Shirkers}

If $\sigma_{t}>\sigma^{*}(0)$ workers are too sick to work and would stay at home even if the replacement rate was equal to zero and they would fully forgo their wage. The utility function in this case approximates $u_{t}=\delta \sigma_{t} l_{t}$. This can be thought of as a state where people are either (i) lying in bed with extremely high fever and heavy, acute, flu symptoms (as an example for a contagious disease), or (ii) lying in bed with heavy disease symptoms, e.g., after chemotherapy in case of cancer (as an example for a non-contagious disease). Empirically, one can estimate that about 3 to $5 \%$ of all workers fall into this category on a given day 10

As sick pay is provided $\left(\alpha_{t}>0\right)$ there will be a share of workers who stay at home due to their sick pay insurance (workers with $\sigma^{*}\left(\alpha_{t}\right)<\sigma_{t}<\sigma^{*}(0)$ ). These individuals would go to work, if there was no sick pay. However, since they receive sick pay benefits, it is rational for them to be absent from work. In the domain of non-contagious diseases, we refer to these workers as shirkers. The share of shirkers at any point in time and for a given sick pay replacement level $\alpha_{t}$ equals

$$
\omega\left(\alpha_{t}\right)=q \int_{\sigma^{*}\left(\alpha_{t}\right)}^{\sigma^{*}(0)} f(\sigma) d \sigma
$$

for non-contagious diseases.

As productivity is hard to measure in most settings, we do not model work productivity explicitly. However, for non-contagious diseases, lower productivity due to sickness mostly dominates sickness absence and zero work output. Formally, denote with $\delta\left(\sigma^{*}(0)\right)$ the sickness-related productivity losses for workers that are just indifferent between going to work and staying at home at a replacement rate of zero. If worker utility and firm profits have similar weights, then as long as $\sigma^{*}(0) \alpha_{t} w>\delta\left(\sigma^{*}(0)\right)$ work is preferred to sickness absence. This condition compares the consumption utility from sickness benefits with the

\footnotetext{
${ }^{10}$ In Germany, on a given day, about $7 \%$ of the workforce are on sick leave (see Section 3.2.
} 
productivity losses from a sick non-contagious worker. Sickness absence is preferred from a societal point of view only if the productivity losses or consumption utility losses due to sickness are very large. For the rest of the paper we assume that $\sigma^{*}(0) \alpha_{t} w>\delta\left(\sigma^{*}(0)\right)$, and thus working is preferred to sickness absence for non-contagious diseases, as long as the disease is not too severe $\sigma_{t}<\sigma^{*}(0)$.

Finally, we define moral hazard as the sum of the fraction of shirking individuals and the fraction of individuals exhibiting contagious presenteeism 11

$$
\rho_{t}\left(\alpha_{t}\right)=\omega\left(\alpha_{t}\right)+\pi_{t}\left(\alpha_{t}\right)
$$

Proposition 1. Under a sick pay scheme and given the existence of contagious as well as non-contagious diseases, there exists a fraction of contagious workers $\pi_{t}$ that engage in presenteeism. Contagious workers who go to work induce negative externalities and infect their co-workers and customers. Likewise, there exists a fraction of workers who shirk, $\omega$, while shirking behavior is determined by non-contagious diseases. Moral hazard, $\rho_{t}$, is the sum of shirking and presenteeism.

In the specification above the main difference between contagious and non-contagious diseases is that contagious diseases lead to contagious presenteeism and infections, which increases the probability of infections. This negative externality is one of the main economic justifications for sick pay. The extent of this negative externality depends on the level of contagiousness of the disease. Therefore, in the context of our model, presenteeism is not harmful per se, but rather the negative externalities generated by presenteeism.

\section{Sick Pay Cuts and Their Impact on Moral Hazard: Intuitive and Graphical Representation}

In order to simplify the analysis, we assume (without loss of generality) that sick pay in the base year $(t=0)$ is high and is exogenously cut after one year in $t=y_{1}$. Deriving the indifference condition in equation $(3)$ yields $\frac{\partial \sigma^{*}(\alpha)}{\partial \alpha}<0$. This means that a decrease in the

\footnotetext{
${ }^{11}$ Similar to Einav et al. (2013) moral hazard is strictly speaking not a hidden action in our context, since it is perfectly observable whether the employee is present or not. It is rather hidden information that employees have about their personal sickness level and their type of sickness.
} 
sick pay replacement rate-as induced by the first German reform in 1996-increases $\sigma^{*}$ and thus more workers work, i.e., the sick leave rate decreases.

Following a sick pay cut, work attendance increases and sick leave decreases. However, what is even more relevant is how contagious presenteeism and shirking behavior changes. It can easily be shown that (i) shirking decreases because $\sigma^{*}\left(\alpha_{y_{1}}\right)>\sigma^{*}\left(\alpha_{0}\right)$. Moreover, (ii) contagious presenteeism increases for the same reason. Thus it remains ambiguous what happens to overall moral hazard since the first component of moral hazard, contagious presenteeism, increases while the second component, shirking, decreases.

Proposition 2. Given the existence of contagious as well as non-contagious diseases, a sick pay cut increases the share of contagious workers who engage in presenteeism and who induce negative externalities by infecting co-workers and customers. At the same time, a sick pay cut reduces the fraction of shirkers. A priori, the impact on moral hazard defined as the sum of both behaviors is ambiguous.

Figure 1 shows a graphical representation of Proposition 2. Panel A depicts the situation for non-contagious diseases. Initially the share of shirkers-indicated by the sum of the two dark gray areas-is quite large. However, as sick pay decreases, some shirkers come to work and the shirking rate and overall absences decrease.

In Panel B we show the situation for contagious diseases. Here all individuals that are working exhibit contagious presenteeism. As sick pay decreases, contagious presenteeism increases. This leads to an increase in the probability of catching a contagious disease $p_{t}$, depicted by an outward shift of the density function.

In the next step, we investigate in more detail how absence rates are affected by a sick pay cut. Exactly the reverse pattern holds for increases in the generosity of sick pay schemes. 
Figure 1: Graphical Representation and Classification of Shares of Working Workers and Workers on Sick Leave

Panel A: Non-Contagious Diseases

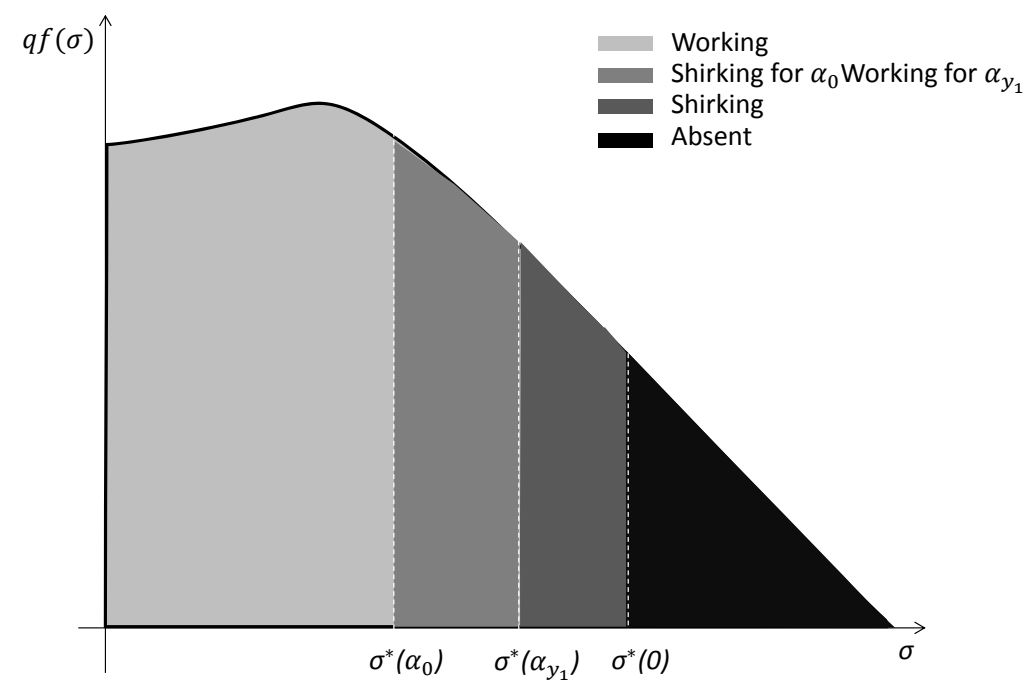

\section{Panel B: Contagious Diseases}

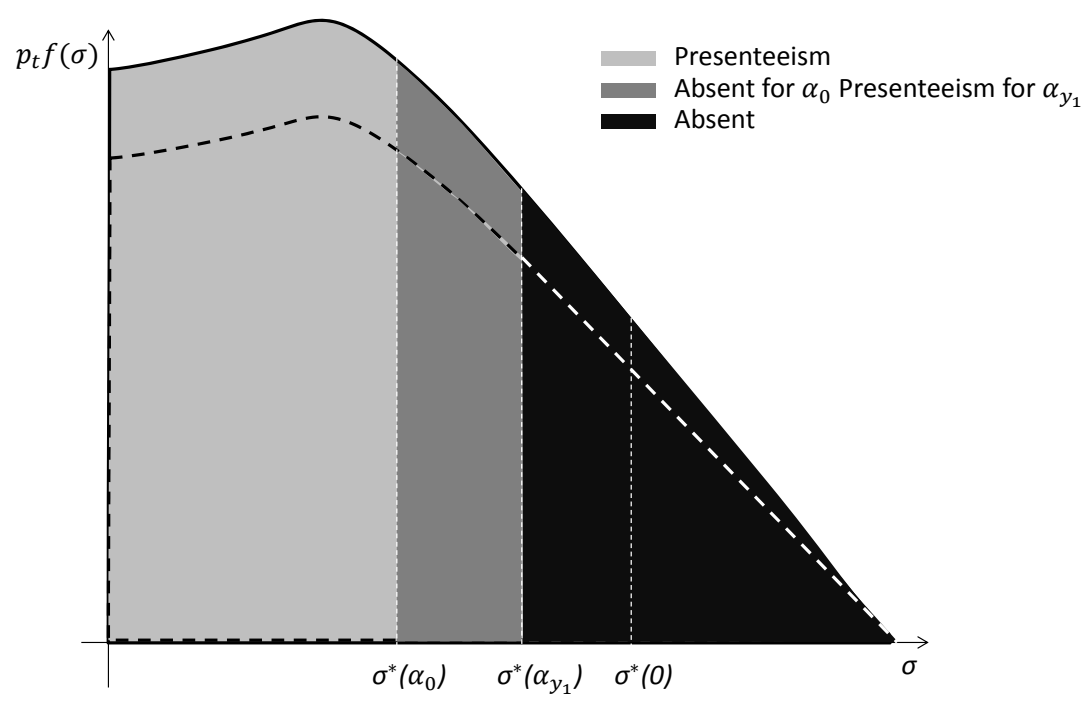

Panel A shows the share of people who draw a non-contagious disease. After the sick pay cut, shirking decreases. In panel B we depict the same situation for contagious diseases. The sick pay cut leads to an increase in presenteeism and in $p_{t}$, represented by the outward shift of the curve. 


\section{Sick Pay Cuts and Their Impact on Moral Hazard: Analytical Derivation}

We denote by $\frac{\Delta A_{n}}{A_{n 0}}=\beta_{n \tau}$ the percentage change in the sick leave rate of non-contagious diseases as the replacement rate decreases, and after $\tau$ time periods have passed; more specifically

$$
\beta_{n \tau}=\frac{1}{A_{n 0}}\left(q \int_{\sigma^{*}\left(\alpha_{0}\right)}^{1} f(\sigma) d \sigma-q \int_{\sigma^{*}\left(\alpha_{\tau}\right)}^{1} f(\sigma) d \sigma\right)=\frac{1}{A_{n 0}}\left(q \int_{\sigma^{*}\left(\alpha_{0}\right)}^{\sigma^{*}\left(\alpha_{\tau}\right)} f(\sigma) d \sigma\right)
$$

As we are in the domain of non-contagious diseases, the reduction in absence is equal to the reduction in shirking when sick pay decreases, and thus we can write

$$
\beta_{n \tau}=\frac{1}{A_{n 0}}\left(\omega\left(\alpha_{0}\right)-\omega\left(\alpha_{\tau}\right)\right)
$$

Similarly we denote by $\frac{\Delta A_{c}}{A_{c 0}}=\beta_{c \tau}$ the percentage change of the sick leave rate of contagious diseases due to a change in the replacement rate after $\tau$ time periods:

$$
\beta_{c \tau}=\frac{1}{A_{c 0}}\left(p_{0} \int_{\sigma^{*}\left(\alpha_{0}\right)}^{1} f(\sigma) d \sigma-p_{\tau} \int_{\sigma^{*}\left(\alpha_{\tau}\right)}^{1} f(\sigma) d \sigma\right)
$$

This expression can be rewritten as

$$
\beta_{c \tau}=\frac{1}{A_{c 0}}\left(\left(\pi_{0}\left(\alpha_{\tau}\right)-\pi_{0}\left(\alpha_{0}\right)\right)-\left(\left(p_{\tau}-p_{0}\right) \int_{\sigma^{*}\left(\alpha_{\tau}\right)}^{1} f(\sigma) d \sigma\right)\right)
$$

where the first element corresponds to the increase in presenteeism (and corresponding decrease in the absence rate) due to the sick pay cut-applying the initial probability of catching a contagious disease $p_{0}$. The second element corresponds to absence created by additional infections due to increased presenteeism.

As described above, infections lead to an increase in the infection rate $p_{t}$. As seen in Proposition 2, more contagious workers work after the sick pay cut. Furthermore, as more workers work, the number of susceptibles increases as well. Both effects result in more infections. Depending on the magnitude of newly infected individuals, the increase in sickness 
absence due to infections at least partly offsets the decrease due to additional contagious presenteeism.

In the next step, we compare the two changes in the sick leave rate, where $\beta_{c \tau}$ and $\beta_{n \tau}$ can be rewritten as:

$$
\beta_{c \tau}=\beta_{n \tau}-\frac{1}{A_{c 0}}\left(\left(p_{\tau}-p_{0}\right) \int_{\sigma^{*}\left(\alpha_{\tau}\right)}^{1} f(\sigma) d \sigma\right)
$$

Therefore the adjustments of shirking and presenteeism with respect to the sick pay cut are exactly equal. Moreover, the adjustments of the two disease groups $\beta_{\mathcal{c} \tau}$ and $\beta_{n \tau}$ only differ by the share of newly infected individuals weighted by the share of individuals on sickness leave before the sick pay cut. Thus, under the existence of contagious presenteeism, it holds that $\beta_{n \tau}>\beta_{c \tau}$. Finally, notice that by definition $\beta_{n \tau}>0$. However-for contagious diseases-the sign of $\beta_{c \tau}$ is unclear. If the disease is very contagious $\beta_{c \tau}$ might become negative. Therefore the sign of $\beta_{c \tau}$ remains an empirical question which can only be answered with appropriate data.

Hypothesis 1 After a sick pay cut the absence rate for non-contagious diseases, i.e. shirking, will decrease $\beta_{n \tau}>0$. For contagious diseases, the sign of $\beta_{c \tau}$ is unclear, since absences due to new infections might outweigh the immediate decrease in the absence rate caused by the increase in presenteeism. Moreover, the difference $\beta_{n \tau}-\beta_{c \tau}$ indicates the additional absences created by infections.

Finally, we denote the overall percentage change with $\beta_{\tau}=\frac{\Delta A}{A_{0}}$ :

$$
\beta_{\tau}=\frac{1}{A_{0}}\left(\left(\omega\left(\alpha_{0}\right)-\omega\left(\alpha_{\tau}\right)\right)+\left(\pi_{0}\left(\alpha_{\tau}\right)-\pi_{0}\left(\alpha_{0}\right)\right)-\left(\left(p_{\tau}-p_{0}\right) \int_{\sigma^{*}\left(\alpha_{\tau}\right)}^{1} f(\sigma) d \sigma\right)\right) .
$$

In the next step we analyze how these effects may be measured using data on sickness absence, in order to quantify the reduction in shirking and the new infections due to the sick pay cut. 


\subsection{Identifying Presenteeism Empirically}

Now assume that we have empirical data on sick leave behavior and a sick leave scheme exists. Furthermore, assume a reform has cut sick pay and we can identify different groups of workers who were affected differently by the reform. Then we can estimate the causal effect of the sick pay cut on the share of workers who call in sick. In the notation above, this means that we can empirically identify the percentage change of sickness absence with respect to the sickness cut $\beta_{\tau}$.

Moreover, assume that we could even empirically identify two different disease categories $_{c}$ and $n$ and the share of employees who call in sick with certified sickness due to contagious and non-contagious diseases. Then one could carry out a statistical test to check if $\beta_{n \tau}>\beta_{c \tau}$. In other words, one could test if the sick pay induced decrease in sick leave is larger for disease categories $n$ as compared to ${ }_{c}$, due to the increased spread of contagious diseases via an increase in contagious presenteeism.

Proposition 4a. Given the existence of a reform that exogenously cut sick pay and data on differently affected employees, one can econometrically test if $\beta_{\tau}>0$, i.e., if the labor supply adjustment with respect to sick pay is positive and, if so, how large it is.

Proposition 4b. Given the additional existence of data for contagious and non-contagious sick leave rates, one can estimate $\beta_{n \tau}$ as well as $\beta_{c \tau}$. The size of $\beta_{n \tau}$ is informative for the relevance of shirking behavior. $\beta_{c \tau}$ estimates a combination of the increase in presenteeism and increase in infections triggered by contagious presenteeism.

Proposition 4c. Additionally, one can econometrically test if $\beta_{n \tau}>\beta_{\mathcal{c} \tau}$ (Hypothesis 1), i.e., whether the decrease in sick leave is larger for non-contagious than for contagious diseases and, if yes, how large the differential is. Finally, the size of the differential represents the existence and the degree of infections-the negative externalities induced by the lower sick pay level. 


\section{The Sick Leave Reforms and Induced Changes in Replace-}

\section{ment Rates}

\subsection{The German Sick Pay Scheme and Monitoring System}

Germany has one of the most generous universal sickness insurance systems in the world. The system is predominantly based on employer mandates. In Germany, employers are mandated to continue wage payments for up to six weeks per sickness episode. In other words, employers have to provide $100 \%$ sick pay from the first day of a period of sickness without benefit caps. 12

In the case of illness, employees are obliged to inform their employer immediately about both the sickness and the expected duration. From the fourth day of a sickness episode, a doctor's certificate is required and is usually issued for up to one week, depending on the illness. However, employers have the right to ask for a doctor's note from the first day of a spell and many employee voluntarily submit doctor's notes from the beginning of a sickness episode.

If the sickness lasts more than six continuous weeks, the doctor needs to issue a different certificate. From the seventh week onwards, sick pay is disbursed by the health insurers (called "sickness funds") and lowered to $80 \%$ of foregone gross wages for those who are insured under Statutory Health Insurance (SHI) 13

The monitoring system mainly consists of an institution called Medical Service of the SHI. One of the original objectives of the Medical Service is to monitor sickness absence. German social legislation codifies that the SHI has the right to call for the Medical Service and a medical opinion to clarify any doubts about work absences. Such doubts may arise if the insured person is short-term absent with unusual frequency or is regularly sick on Mon-

\footnotetext{
12 The entitlement is codified in the so-called Gesetz über die Zahlung des Arbeitsentgelts an Feiertagen und im Krankheitsfall (Entgeltfortzahlungsgesetz), article 3, 4.

${ }^{13}$ In principle, there is no limit on the frequency of sick leave spells. However, if employees fall sick again due to the same illness after an episode of six weeks, the law explicitly states that they are only again eligible for employer-provided sick pay if at least six months have been passed between the two spells or twelve month have been passed since the beginning of the first spell. This paragraph intends to avoid substitution of long-term spells by short-term spells.
} 
days or Fridays. Similarly, if doctors certify sickness with unusual frequency, the SHI may ask for expert advice. The employer also has the right to call for the assistance of the Medical Service and expert advice. Expert advice is based on available medical documents, information about the workplace, and a statement which is requested from the patient. If necessary, the Medical Service has the right to conduct a physical examination of the patient and to cut benefits. 14 In 2012, about 2,000 full-time equivalent and independent doctors worked for the medical service and examined 1.5 million cases of absenteeism (Medizinischer Dienst der Krankenversicherung (MDK), 2014).

\subsection{The Policy Reforms}

In 1996, the total sum of employer-provided sick pay amounted to EUR 28.2 billion or 1.5\% of GDP (German Federal Statistical Office, 1998). It was though of as a tax on labor and was attributed with unemployment rates. In addition there were speculations of a high degree of shirking behavior. Relating the average number of sick days per year to the annual number of hours worked per employee shows that more than $7 \%$ of the annual working time was "lost" (Bundesverbank der Betriebskrankenkassen (BKK), 2004; Hans Böckler Stiftung, 2014). These considerations incited the German center-right government to pass a Bill to Foster Growth and Employment which became effective on October 1, 1996.15 Panel A of Table 1 summarizes the changes in the federal employer mandate due to this bill.

\footnotetext{
14 The wording of the laws can be found in the Social Code Book V, article 275, para. 1, 1a; article 276

${ }^{15}$ Passed on September 25, 1996 this law is the Arbeitsrechtliches Gesetz zur Förderung von Wachstum und Beschäftigung (Arbeitsrechtliches Beschäftigungsförderungsgesetz), BGBl. I 1996 p. 1476-1479.
} 
Table 1: Detailed Overview of Reductions and Increases in Federal Employer Sick Pay Mandates and Industry-Specific Collective Agreements

\begin{tabular}{|c|c|c|c|}
\hline 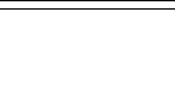 & $\begin{array}{l}\text { Before 10/1996 } \\
\text { (1) }\end{array}$ & $\begin{array}{l}\text { 10/1996-12/1998 } \\
\text { (2) }\end{array}$ & $\begin{array}{l}\text { Since 1/1999 } \\
(3)\end{array}$ \\
\hline \multicolumn{4}{|c|}{ Panel A: Federal Employer Mandate Regulations } \\
\hline & $\begin{array}{l}100 \% \text { sick pay } \\
\text { No waiting period for new employees } \\
\text { Paid overtime included in basis of calculation } \\
\text { Extra payments included in basis of calculation }\end{array}$ & $\begin{array}{l}80 \% \text { sick pay } \\
\text { Waiting period } 4 \text { weeks } \\
\text { Paid overtime included in basis of calculation } \\
\text { Extra payments can be contractually excluded } \\
\text { No cut if } 1 \text { day of paid vacation traded for } 5 \text { sick days }\end{array}$ & $\begin{array}{l}\text { 100\% sick pay } \\
\text { Waiting period } 4 \text { weeks } \\
\text { Paid overtime excluded in basis of calculation } \\
\text { Extra payments can be contractually excluded }\end{array}$ \\
\hline $\begin{array}{l}\text { Panel B: In } \\
\text { Group I }\end{array}$ & \multicolumn{3}{|c|}{ Panel B: Industry-Specific Collective Bargaining Regulations } \\
\hline Group II & & $\begin{array}{l}100 \% \text { sick pay } \\
\text { Paid overtime excluded in basis of calculation }\end{array}$ & \\
\hline Group III & & $100 \%$ sick pay & \\
\hline \multicolumn{4}{|c|}{ Panel C: Combined Effect for Different Industries } \\
\hline Group I & as in Panel A & $\begin{array}{l}80 \% \text { sick pay, since } 07 / 97 \text { during first } 3 \text { days } \\
\text { Waiting period } 4 \text { weeks }\end{array}$ & $\begin{array}{l}\mathbf{1 0 0} \% \text { sick pay } \\
\text { Waiting period } 4 \text { weeks } \\
\text { Paid overtime excluded in basis of calculation }\end{array}$ \\
\hline Group II & as in Panel A & $\begin{array}{l}100 \% \text { sick pay } \\
\text { Waiting period } 4 \text { weeks } \\
\text { Paid overtime excluded in basis of calculation }\end{array}$ & $\begin{array}{l}100 \% \text { sick pay } \\
\text { Waiting period } 4 \text { weeks } \\
\text { Paid overtime excluded in basis of calculation }\end{array}$ \\
\hline Group III & as in Panel A & $\begin{array}{l}100 \% \text { sick pay } \\
\text { Waiting period } 4 \text { weeks }\end{array}$ & $\begin{array}{l}100 \% \text { sick pay } \\
\text { Waiting period } 4 \text { weeks } \\
\text { Paid overtime excluded in basis of calculation }\end{array}$ \\
\hline \multicolumn{4}{|c|}{$\begin{array}{l}\text { Source: (Hans Böckler Stiftung, 2014), own illustration. Group I is composed of the construction sector. Group II contains the following industries: steel, textile, } \\
\text { mechanical engineering, automobile, ship and aerospace, electrical engineering and optics, wood and paper, printing, food and hospitality, trade, banking and } \\
\text { insurance. Group III represents the chemical, oil, glass, energy and water, postal and transportation as well as public administration sector. Changes in regulation } \\
\text { between time periods are in bold. The negotiated agreements cover } 1.1 \mathrm{M} \text { employees in Group I and at least } 4.5 \mathrm{M} \text { in Group II and } 4 \mathrm{M} \text { in Group III (Jahn, |1998, |Hans } \\
\text { Böckler Stiftung, 2014). }\end{array}$} \\
\hline
\end{tabular}




\section{Sick Pay Cut at the End of 1996}

As seen in Table1, the bill reduced the sick pay obligations of private sector employers from $100 \%$ to $80 \%$ of foregone wages ${ }^{16}$ For obvious reasons, self-employed were not affected by this change in the employer mandate ${ }^{17}$ Private sector employees on sick leave due to work accidents were also unaffected by the bill, being explicitly excluded from the cut in sick pay.

In addition to the reduction in the level of sick pay, a four week waiting period for new employees was introduced (Panel A of Table 1). Moreover, the bill introduced two options: (a) The first allowed employers to contractually exclude extra payments from the basis of calculation to which the replace rate is applied. (b) The second allowed employees to swap one day of paid vacation for five days of sick leave, thereby avoiding the cut to $80 \% \cdot 18$ It is unclear to what degree these new options were applied by employees and employers. Since we do not have any information on their relevance and also could not find explicit information on their use in industry-specific collective agreements, henceforth, we assume that they were either of minor relevance or were not applied systematically in specific industries (and thus abstain from commenting on them further). A scattered application of these two options should not significantly bias our empirical findings.

Both before and after the bill's implementation, through mass demonstrations and strikes, the general public and unions put pressure on employers' associations to not apply these less generous minimum standards. Germany is the country of origin of Bismarckian corporatism, which has served as a model for several European countries. An integral part of Bismarckian corporatism is the idea of social partnership between employers and unions

\footnotetext{
${ }^{16}$ In addition to this bill that lowered employer-mandated sick pay, another bill cut long-term sick pay from the seventh week onwards from $80 \%$ to $70 \%$ of forgone gross wages. Ziebarth (2013) shows that this second bill did not induce significant behavioral reactions among the long-term sick.

${ }^{17}$ Figure 2 of Ziebarth and Karlsson (2010) illustrates the overall structure of affected and unaffected employees in Germany. Due to political considerations and the existence of other laws, public sector employees were exempt from the reform. This paper solely focuses on the implementation at the industry level among employees who were covered by collective agreements, i.e., up to 15 million private sector employees plus up to 5 million in public administration (see Table 17. The empirical part is solely based on those employees who were enrolled in one of the 690 (out of 960) company-specific health plans ("Betriebskrankenkassen") (German Federal Statistical Office. 2014).

${ }^{18}$ Note that this option was likely introduced to dampen potential presenteeism by low-wage employees who could not afford to forgo $20 \%$ of their daily wage. Those employees would not suffer a monetary loss if this option was drawn, but "lost" one day of paid vacation for five sick days, which is the monetary equivalent to a daily cut by $20 \%$.
} 
as well as autonomy in bargaining. As a result, unions are traditionally strong in Germany as is the degree of collective bargaining coverage. In 1998, about $68 \%$ of all employees in West and 50\% in East Germany were covered by collective wage agreements (Hans Böckler Stiftung, 2014).

Ongoing union pressure forced employer associations in various industries to agree, through collective agreements, to voluntarily provide sick pay on top of the statutory regulations. Further, the question of whether employees in specific industries were entitled to claim $100 \%$ or $80 \%$ of their salary during sickness episodes was determined by existing collective agreements and their legal interpretation. Some existing agreements explicitly, but probably coincidentally, stated that sick pay would be $100 \%$, while others did not mention sick pay at all. In the former case, sick pay would remain $100 \%$ despite the decrease in the generosity of the employer mandate, while sick pay would decrease in the latter case to $80 \%$ until a revised agreement was negotiated.

Review of Collective Agreements. Similar to Ziebarth and Karlsson (2010) and Ziebarth and Karlsson (2014), we reviewed all collective agreements that were implemented during the same time period of the two sick pay reforms and categorized industries. Overall, one can distinguish three different groups and industries that implemented the following sick leave regulations in their collective agreements on the industry level. Panel A of Table 1 shows the federal regulation, whereas Panel B provides the provisions at the industry level and our categorization.

Group I is composed of the construction sector. The existing collective agreement covered about 1.1 million private sector workers. ${ }^{19}$ When the law was passed, this existing collective agreement did not include any explicit provision on sick pay, which is why the entire federal regulations applied to the construction sector at the time of the bill's implementation. A negotiated compromise between unions and employers resulted in a new agreement which became effective July 1, 1997. This new agreement specified that the cut in the replacement rate would only be applied during the first three days of a sickness episode 20

\footnotetext{
${ }^{19}$ In total Germany counted about 25 million private sector workers at that time.

${ }^{20}$ In 1997 a minimum wage in the construction sector was introduced. Theoretically a wage increase should also lead to a reduction in sickness absence. However, Blien et al. (2009) and Rattenhuber (2011) only find
} 
Group II has at least 4.4 million covered employees and is quantitatively the largest group. It includes eleven industries as specified in the notes to Table 1, among them the steel, textile and automobile. Union leaders in these industries managed to maintain the symbolically important $100 \%$ sick pay level. However, in return, they had to agree to exclude paid overtime from the basis of calculation for sick pay.

Excluding overtime from the basis of calculation effectively means that employees with a significant amount of overtime hours experienced sick pay cuts. However, there are several reasons why one could suspect that this type of sick pay decrease may be of minor relevance: (a) Fraction of Employees Effectively Affected. As representative SOEP data show, among BKK insurees (which our main dataset is composed of), only 19\% had paid overtime hours in 1998, the average being 4 hours per week (SOEPGroup, 2008). (b) Size of Cut. While a decrease in the base rate to $80 \%$ would reduce net sick pay by $280 €$ per month (in 1998 values), the exclusion of paid overtime would only lead to a net cut of $110 €$ per month (in 1998 values), conditional on working overtime and getting paid for it.21 (c) Salience of Cut. While maintaining the 100\% replacement level had a high symbolic meaning for unions, the indirect reductions in sick pay were not communicated as openly, and it is questionable if every employee was aware of them. (d) Affected individuals. One could suspect that employees with paid overtime hours might be highly motivated employees in leading positions with a low number of sick days and a low propensity to shirk. However, as the SOEP shows, employees with paid overtime had on average 10 sick days per year while those without paid overtime hours had only 4.7 sick days.

Group III is composed of seven industries, all of which stated in their collective agreements that they would maintain 100\% sick pay. Moreover, in contrast to Group II, these industries did not exclude overtime payments from the basis of calculation. Hence the 4 million employees covered by these agreements serve as control group in the evaluation of the 1997 sick pay cut.

small effects in East Germany which are no threat to the application of our method and the general empirical findings.

${ }^{21}$ Again, both figures are taken from representative weighted SOEP data (SOEPGroup, 2008). The first is $20 \%$ of the average monthly net wage for BKK insurees in 1998. The second takes the hourly net wage for BKK insurees in 1998, which was about $€ 7$, and multiplies it with the average number of paid overtime hours per month for this group, which is about 16. 
As detailed below, we use administrative data based on mandatorily insured SHI employees who are covered through small company-specific health plans ("Betriebskrankenkassen" (BKKs)). In 1995, before the first reform, switching between public health plans was not possible and employees were assigned to company-specific health plans if their employer offered such plans (which was not mandatory and mostly large and well known employers offered such plans). In 1995, a total of 960 public health plans existed in Germany, and 690 or $72 \%$ of them were BKKs (German Federal Statistical Office, 2014). Employees insured under these health plans were likely covered by binding collective agreements.

As Table 1 shows, the empirical analysis is based on the three groups of employees who were treated differently through a combination of changes in the federal employer mandate and its interaction with existing and new collective agreements on the industry level.

\section{Reversal of Main Sick Pay Cut 1999 and Remaining Changes}

In September 1998, a federal election was held in Germany. This election came after conservative Chancellor Helmut Kohl's 16 year tenure, who, in the last years of his governance became unpopular and was considered a lame duck. In their 1998 election campaign, the two opposition parties Social Democrats and Greens promised to increase federally mandated sick pay again from $80 \%$ to $100 \%$ should they form a new coalition government. Obviously, the campaign promise was a reaction to the sick pay cut under the previous center-right government.

Immediately after the election was won by the new center-left coalition, the Bill for Social Insurance Corrections and to Protect Employee Rights was passed ${ }^{22}$ It went into effect on January 1, 1999, increasing federally mandated sick pay again from $80 \%$ to $100 \%$ of foregone gross wages (see Table 1). However, as Table 1 also illustrates, while the main provision was reversed, two minor-but potentially important—details were making the new status quo after 1999 less generous than the old one before October 1996. And in combination with the meanwhile negotiated collective agreements they affected the three groups in Table 1 differently.

\footnotetext{
${ }^{22}$ Passed on December 19, 1998, in German this law is the Gesetz zu Korrekturen in der Sozialversicherung und zur Sicherung der Arbeitnehmerrechte, BGBI.I 1998 Nr. 85 S.3843-3852.
} 
First, the four week waiting period-introduced in October 1996-was maintained. However, since-to our knowledge-no collective agreement excluded this waiting period, none of the three groups was affected by this decision between 1997/1998 and post-1999. Second, the second bill explicitly included a provision that stated that paid overtime hours would be excluded from the basis of calculation. This provision was not part of the 1996 reform bill. It was probably a reaction to the many collective agreements that already implemented such a provision at the industry level. However, since no industry in Group I and III of Table 1 had such a provision in their collective agreements, ironically, Group III's sick pay became less generous as a result of the new bill. In our research, we did not find any evidence that unions (successfully) tried to negotiate an exclusion of this provision in post-1999 agreements.

Thus, overall, for the evaluation of the 1999 reform, Group II serves as the main control group that did not experience any sick pay scheme changes between 1997/1998 and 1999 . Group III was treated and their sick pay scheme became less generous due the exclusion of paid overtime from the basis of calculation ${ }^{23}$ Again, as in 1996, Group I serves as the main treatment group whose sick pay level was increased from $80 \%$ to $100 \%$. Note, however, that in addition to this level increase their overtime was excluded from the basis of calculation, making the net impact of the simultaneous increase and decrease in generosity theoretically ambiguous. To net out the impact of the overtime exclusion, we contrast their change in sick leave rates with Group III.

\footnotetext{
${ }^{23}$ The roles of Group II and Group III were reversed in the 1996 reform, which should be kept in mind when interpreting the coefficient estimates below which contrast Group II with Group III.
} 


\section{Data, Variables, and Empirical Specification}

\subsection{Digitized Administrative Data on Disease-Specific Sickness Absence:} 1994-2004

In Germany certified sickness absence spells, including diagnoses, are recorded by sickness funds ("Gesetzliche Krankenversicherungen (GKV)"). Sickness funds are non-profit health plans that belong to the Statutory Health Insurance (SHI) system under which $90 \%$ of the German population is insured. Currently 130 different sickness funds exist and enrollees are covered by a standard health plan that is heavily regulated under social law. Switching rates are low and around 5\% (cf. Eibich et al., 2012; Schmitz and Ziebarth, 2013, for a description of the German system).

Historically, switching between sickness funds was not possible and enrollees were assigned to a sickness fund based on occupation and industry. More precisely, more wellknown companies typically administer their own company-based sickness fund, intended to cover all employees of that company. This is similar to employment-provided coverage in the US, but with automatic enrollment. These company-based sickness funds are called Betriebskrankenkassen (BKK). 1995 was the last year before switching between different sickness funds became an option. However, according to the SOEP, $96.4 \%$ of employees remained ensured within the BKK system between 1994 and 1995. This value remained high the next two years, at $96.6 \%$ and $96.8 \% .{ }^{24}$

The federal association of company-based sickness funds ("BKK Dachverband") annually publishes details on the sickness absence behavior of their 4.8 million enrollees who are mandatorily SHI insured and gainfully employed (19\% of all private sector employees

\footnotetext{
${ }^{24}$ The fact that a small percentage of employees even switched before it was officially an option is due to one of the following reasons: they either (i) opted out of the public system and insured their health risk privately, which is possible under certain conditions in Germany, or (ii) switched employers, or (iii) switched to their spouse's family plan.
} 
(Bundesverbank der Betriebskrankenkassen (BKK), 2004)) ${ }^{25}$ The Krankheitsartenstatistik ${ }^{26}$ reports both the incidence as well as the length of sickness spells by gender, age group, ICD diagnoses, and industry. We collected and digitized information from over a decade of annual reports from 1994 to 2004 (Bundesverbank der Betriebskrankenkassen (BKK), 2004).27 The descriptive statistics are in the Appendix, Table A1

In total, we count 1,188 observations, where each observation represents one industry and year as well as the diagnosed sickness category. More specifically, we count 11 years and 18 industries which adds up to 198 industry-year observations per diagnosis category.

\subsection{Sick Leave Variables Generated and Treatment Groups Defined}

\section{Generated Sick Leave Variables}

Our outcome variable is the sick leave rate. This variable counts the number of certified sickness spells, normalized per 100 enrollees (sick cases per 100 enrollees). We transform each dependent variable by taking the logarithm in order to look at percentage changes discussed in section 2 .

Figure $2 \mathrm{a}$ shows the distribution of total sick cases per 100 enrollees and Figure $2 \mathrm{~b}$ its logarithm. In both cases we observe a relatively symmetric, close to normal, distribution. The untransformed plain variable has a mean of 125 , which means that one observes 1.25 sick leave cases per year and enrollee across all industries and years. However, the variation ranges from 90 to 163 (Figure 2a and Table A1).

\footnotetext{
${ }^{25}$ Although, strictly speaking, BKKs are not legally obliged to contribute to the Krankheitsartenstatistik, the overwhelming majority does, probably simply out of tradition to contribute to this important statistic that has been existing since 1976. In 2013, more than $90 \%$ of all mandatorily insured BKK enrollees were covered by the Krankheitsartenstatistik (Bundesverbank der Betriebskrankenkassen (BKK), 2004, German Federal Statistical Office, 2014). There is no evidence that this share systematically varied due to the reforms.

26 Today, the newly founded BKK Dachverband (until December 31, 2013 called Bundesverbank der Betriebskrankenkassen) calls it Gesundheitsreport ("Health Report").

${ }^{27}$ We cannot use earlier data due to a lack of consistency that goes back to an earlier reform.
} 
Figure 2: Distribution of (a) Sick Leave Cases and (b) Logarithm of Sick Leave Cases per 100 Insurees
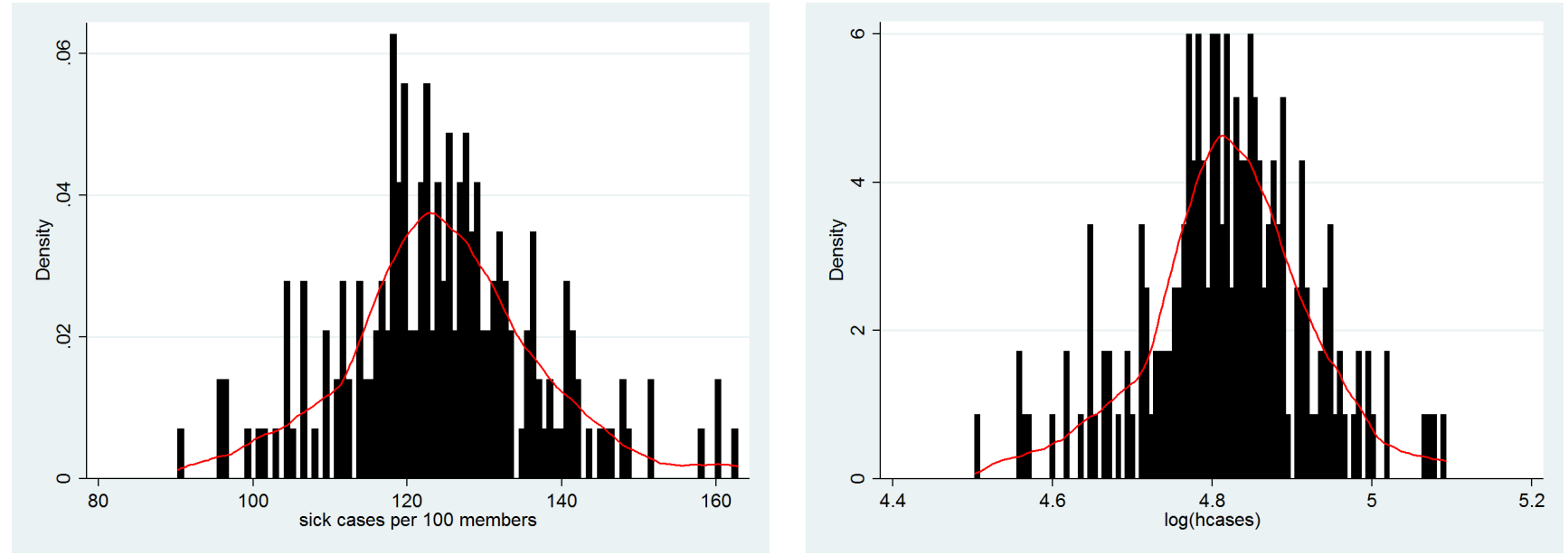

Looking at the other disease categories and their incidence rates, one finds that the largest disease group is respiratory diseases, ICD codes J00-J99, contributing 29\% of all cases. Within this group, a third of all cases are due to "bronchitis (J20)", while a quarter is due to “influenza (J09)." Moreover, another fifth is caused by "acute upper respiratory infections (J06)."

The second largest disease group with almost $20 \%$ of all cases is musculoskeletal diseases (M00-M99), which have the reputation to be particularly prone to shirking behavior. The most noteworthy subcategory in this group is "dorsalgia - back pain (M54)" making up $70 \%(!)$ of all cases.

Next in terms of their incidence relevance are digestive diseases (K00-K93, 14\%), injuries and poisoning (S00-T98, 11\%), followed by infectious (A00-B99, 6\%) and mental (F00-F99, $2 \%$ ) diseases. The most common digestive disease is "non-infective gastroenteritis (K52, $45 \%)$ ". Infectious diseases are mainly made up of "viral infections (B34)" and "infectious gastroenteritis (A09)." Together over $80 \%$ of all cases coded as infectious diseases fall in these two subcategories.

\subsection{Empirical Model and Identification}

We estimate the following conventional parametric Difference-in-Differences (DiD) model separately for different disease categories: 


$$
\begin{aligned}
\log \left(y_{i t}\right) & =\alpha_{i}+\beta_{0}+\beta_{1} \text { Group } I_{i} \times{ }^{\prime} 97-^{\prime} 98+\beta_{2} \text { Group }_{i} \times{ }^{\prime} 99-^{\prime} 04+ \\
& \beta_{3} \text { GroupII }_{i} \times^{\prime} 97-^{\prime} 98+\beta_{4} \text { Group II }_{i} \times{ }^{\prime} 99-^{\prime} 04+ \\
& +\delta_{t}+\mu_{i t}
\end{aligned}
$$

where $\log \left(y_{i t}\right)$ stands for one of our dependent sick leave measures as discussed above for industry $i$ at time $t . \gamma_{i}$ are 17 industry fixed effects and $\delta_{t} 10$ year fixed effects. The standard errors are routinely clustered at the industry level. We interact the treatment indicators as defined below with two time period dummy variables '97-'98 and '99-'04. The reference period are the years 1994 to 1996.

Group $_{i}$ as well as GroupII $I_{i}$ are binary treatment indicators. Group $I_{i}$ is 1 for Group I in Table 1 and 0 for Group II and Group III. This means that $\beta_{1}$ identifies the sick pay cut effect from $100 \%$ to $80 \%$ for Group I relative to the control Group III in 1997/1998 relative to the pre-reform years 1994 to 1996. Moreover, $\beta_{2}$ measures the post-1999 sick leave level relative to the the pre-1997 level, or the joint effect of the two reforms, i.e., the sick pay cut in '96 and the reversal in '99. Recall that the entire system was less generous post-1999 since it excluded overtime from the basis of calculation and included a waiting period, which was not the case pre-1997. Finally, the difference $\beta_{2}-\beta_{1}$ identifies the effect of the increase in the sick pay level from $80 \%$ to $100 \%$ after 1999 relative to $1997 / 1998$.

Group II $_{i}$, by contrast, is one for Group II and zero for Group I and Group III. As shown in Table 1 , this means that $\beta_{3}$ identifies the effect of excluding paid overtime, i.e., a soft sick pay cut, for Group II in 1997 and 1998, relative to pre-reform. In contrast, $\beta_{3}-\beta_{4}$ identifies the effect of the overtime exclusion for Group III in the post 1999 era relative to pre-1999.28

Since the outcome measures are in logarithms, $\beta_{1}$ to $\beta_{4}$ directly provide the reformrelated change of the outcome variable in percent-should the common time trend assumption hold. The Results section investigates and shows graphically that the common time

\footnotetext{
${ }^{28}$ Recall that overtime was excluded for Group II in 1997 while nothing happened to Group III, whereas in 1999, overtime was excluded for Group III while nothing happened to Group II. Consequently, $-\beta_{4}+\beta_{3}$ identifies the estimate of the ' 99 overtime exclusion for Group III.
} 
trend assumption - which is the main identifying assumption in DiD models—is likely to hold in this setting.

Moreover, to directly test our model predictions, in a second step, we pool all disease categories and estimate:

$$
\begin{aligned}
& \log \left(y_{\text {dit }}\right)=\alpha_{d i}+\beta_{0}+\beta_{1} \text { Group }_{i} \times^{\prime} 97 \text { - }^{\prime} 98+\beta_{2} \text { Group }_{i} \times{ }^{\prime} 99-^{\prime} 04+ \\
& \beta_{3} \text { GroupII }_{i} \times{ }^{\prime} 97-{ }^{\prime} 98+\beta_{4} \text { GroupII }_{i} \times{ }^{\prime} 99-{ }^{\prime} 04+ \\
& \gamma_{i 1} \text { GroupI }_{i} \times{ }^{\prime} 97-{ }^{\prime} 98 \times \text { Dis }_{d}+\gamma_{i 2} \text { GroupI }_{i} \times{ }^{\prime} 99-^{\prime} 04 \times \operatorname{Dis}_{d}+ \\
& \gamma_{i 3} \text { GroupII }_{i} \times{ }^{\prime} 97-^{\prime} 98 \times \text { Dis }_{d}+\gamma_{i 4} \text { GroupII }_{i} \times{ }^{\prime} 99-^{\prime} 04 \times \text { Dis }_{d}+ \\
& +\delta_{d t}+\mu_{d i t}
\end{aligned}
$$

Where $\alpha_{d i}$ and $\delta_{d t}$ are disease specific industry and time fixed effects, $D i s_{d}$ is a dummy variable equal to one for disease $d$ and zero for all other diseases. This estimation represents a triple DiD model, where the first difference is between the treatment groups, the second difference is between time periods and, finally, the third difference is in terms of diseases. Therefore, in this equation, the estimates for $\gamma$ directly indicate how the reform effect for every disease considered differs from the baseline disease effect.

\section{Results}

\subsection{Graphical Evidence}

Figure 3 shows the "Development of Normalized Sick Leave Cases by Treatment Groups", or the outcome variable sick leave rate by the three treatment groups over time. Sick leave rate is defined as the number of sickness cases per 100 enrollees. Figure 3 a shows the development of the overall sick leave rate, Figure $3 \mathrm{~b}$ looks at musculoskeletal diseases, while Figures $3 c$ and $d$ plot diseases of the respiratory system and infectious diseases. In addition to being normalized by the number of enrollees, these graphs are also normalized with 
respect to the reference year 1994, which is indexed as 100. The two black vertical bars indicate the official implementation dates of the cut and increase in sick pay generosity. The grey shaded area represents $95 \%$ confidence intervals. The representation in Figure 3 serves two main purposes: (a) to examine the plausibility of the common time assumption, (b) to anticipate and visually illustrate the main findings and help understand how they identify the model in Section 2 .

The main identifying assumption in DiD models is the common time trend assumption. It assumes that the outcome variables of all treatment and control groups would have developed in a parallel manner absent the treatment. The standard way to inspect its plausibility is to plot the outcome variables for the different groups graphically and assess their potentially parallel development.

Overall, Figure 3 shows us the following: First, in general, the common time trend assumption is very likely to hold in this setting. Despite some minor spikes here and there, it is obvious that all three groups in the four graphs develop in a pretty parallel manner over the 11 years without reform. In the graphs, this is the case for the time periods before 1997 and after 2000. In particular Figure $3 \mathrm{~d}$ - showing infectious diseases - illustrates a remarkably parallel development (and does not provide any graphical evidence for a reform effect).

Second, with the exception of infectious diseases, the other three graphs provide strong evidence of a significant reform effect for Group I during the first three days of a spell (see Table 1). Immediately after the reform implementation, we observe a $20 \%$ decrease in the sick leave rate for the overall disease category: ${ }^{29}$ For musculoskeletal diseases, the decrease is almost twice as large, and is only half as large for respiratory diseases-the disease category that includes, among others, flues and common colds. The gap between different groups as a result of the sick pay cut unambiguously, not but entirely, closes after 2000. This suggests that (a) the behavioral reaction after the reversal of the sick pay cut is delayed in kicking in. This is probably due to the low media coverage of the reversal law relative to the initial cut, which caused mass demonstrations. Moreover, (b) there is evidence for time persistence or habit formation in sick leave behavior, since the regulations were again identical

\footnotetext{
${ }^{29}$ This is in line with the two other existing studies evaluating this reform using SOEP data (Ziebarth and Karlsson, 2010: Puhani and Sonderhof, 2010)
} 
for all three groups post-1999 (Table 1) and all three groups started with the same initial sick leave level prior to 1997. However, we still observe significant differences between the three groups, even as late as in 2004.

Figure 3: Development of Normalized Sick Leave Cases by Treatment Groups
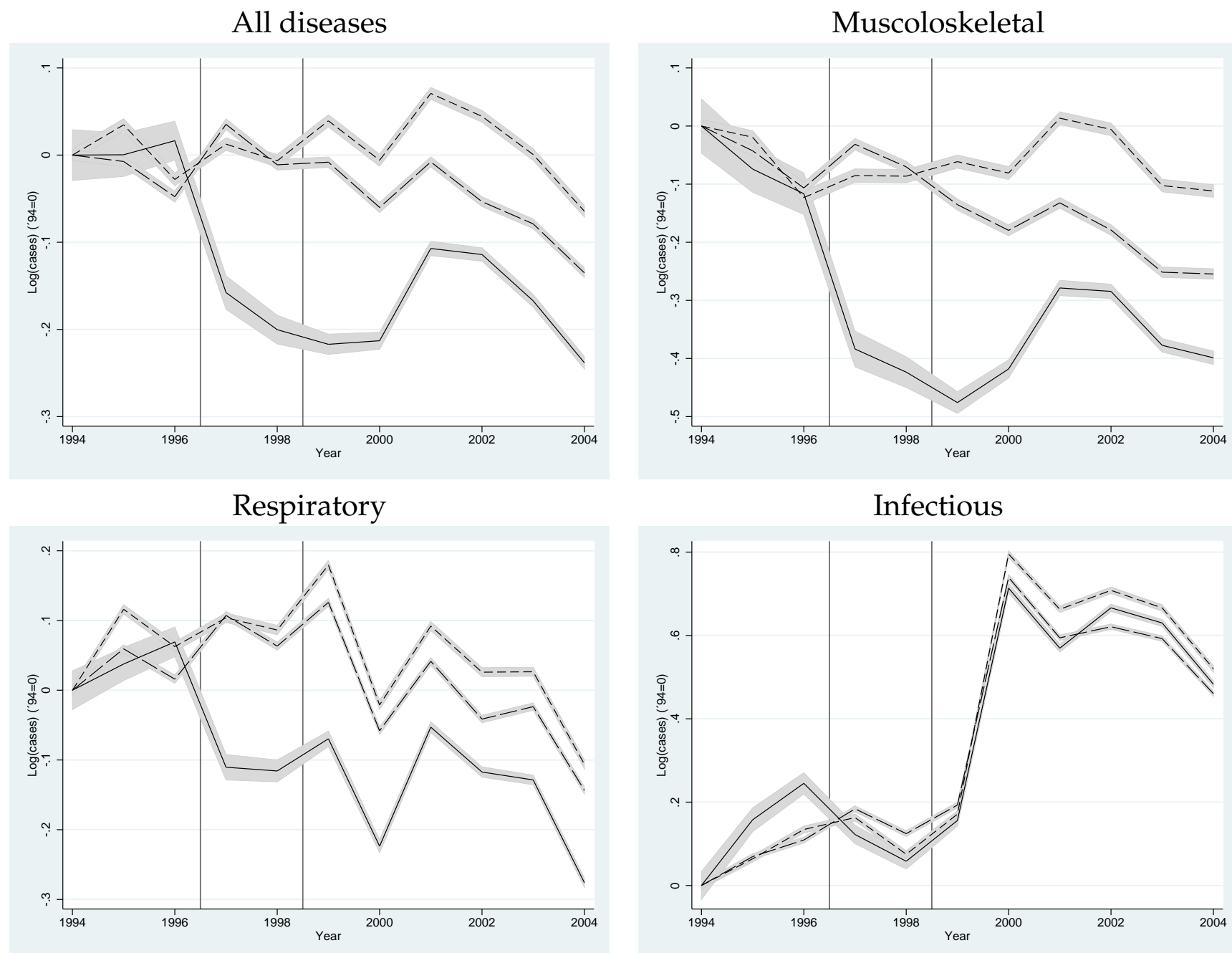

The solid line shows the development of industries in Group I with the corresponding 95\% confidence interval. This group experienced a sick pay cut from 100\% to 80\% in 1997 and the reverse of this cut in 1999. The short dashed line represents Group II. This group witnessed a "soft cut" in 1997 through the exclusion of overtime. Finally, the long dashed line depicts Group III, which had a soft cut in 1999. For more information about the sick pay reforms, see Table 1 .

Third, and interestingly, while we find clear evidence for reform effects among Group I after both reforms, the reaction to the soft sick pay cut-excluding overtime from the basis of calculation-was asymmetric. While there seems to be no evidence that excluding overtime affected Group II's behavior in 1997 and 1998, we do find graphical evidence suggesting that the very same measure had a significant impact on Group III post 1999. There are two potential explanations for this finding. (a) Relevance of Relative Changes. The decrease in 
sick pay at the end of 1996 was heatedly debated in German society and led to strikes. The main (media) focus was clearly on the decrease in the overall sick pay level. It is plausible that Group II did not react since the main reference point mattered here, which was the decrease in the default federal level. About $50 \%$ of all employees experienced a decrease in the level to 80\% (Ridinger, 1997; Jahn, 1998). Hence the exclusion of overtime pay was, relatively seen, negligible for affected workers. It may not even have been noticed by the affected employees. After unions managed to negotiate the general sick pay level to remain at $100 \%$, they marketed and emphasized this success accordingly-but either did not mention, or heavily down played the overtime cut. In 1999, by contrast, the exclusion of paid overtime was the only regulatory change that made employees worse off. (b) LATE. Since the model identifies the Local Average Treatment Effect (LATE), it could simply be that paid overtime was more relevant for Group III than for Group II.

Finally, relating these findings to our model in Section 2, one can summarize that (i) there is clear evidence for a significant and persistent decrease in the absence rate, $\beta_{\tau}>0$ (Proposition 4a). Moreover, (ii) we find that the total percentage adjustment of contagious diseases is smaller than the adjustment of non-contagious diseases and thus Proposition $4 c, \beta_{n \tau}>\beta_{c \tau}$, holds up. In addition, we find a large decrease in shirking $\beta_{n \tau}>0$ while the increase in presenteeism outweighs additional infections $\beta_{c \tau}>0$ (Proposition $\left.4 \boldsymbol{b}\right)$. Finally, since (iii) $\beta_{n \tau}-\beta_{c \tau}>0$, the reform being studied also led to an increase in infections (Proposition $4 b)$.

\subsection{Evidence from Regression Models: Sickness Adjustments by Dis- eases}

\section{Disease-Specific Labor Supply Adjustments: Decomposing Moral Hazard}

Estimating $\hat{\beta}_{\tau}, \hat{\beta}_{n \tau}$, and $\hat{\beta}_{c \tau}$. Table 2 shows the results of the regression model in equation (15) using different outcome variables: the logarithm of sick cases per 100 enrollees by the disease categories total, musculoskeletal, digestive, infectious, respiratory, and injuries \& poisoning. Each column is one model as in equation (15). For illustrative purposes, we 
solely show the coefficients of $\beta_{1}$ to $\beta_{4}$ and suppress the remaining ones. In the row below the $\beta_{1}$ to $\beta_{4}$ coefficient estimates, we (a) display the results of an F-test $\beta_{2}-\beta_{1}=0$ to test the effect of the sick pay level increase in 1999 for Group I relative to Group III. As discussed in Section 4.3 , the empirical models closely identify the theoretical model. For example, $\beta_{1}$ in the first row of the first column of Table 2 estimates $\beta_{\tau}$ in equation (14) and tests Proposition 4a. The finding is then cross-checked by $\beta_{2}-\beta_{1}=0$ which likewise test Proposition $4 a$ using the increase in sick pay as as an exogenous source of variation.

Note that the overtime exclusion, or "soft sick pay cut" as we call it, essentially also tests Proposition $4 \boldsymbol{a}$ and the size and sign of $\beta_{\tau}$ in equation (14) since any variant of making the sick pay less generous could be interpreted as a decrease in sick pay. However, we believe that the best suited coefficient estimates to test Propositions $4 a-c$ are the ones resulting from GroupI $_{i} \times^{\prime} 97$ - '98 - the $\beta_{1}$ s for the different disease categories. These are the effects of the initial reduction in the sick pay replacement rate from $100 \%$ to $80 \%$ in $1997 / 1998$. However, we double and cross-check the consistency and plausibility of these main $\beta_{1}$ findings using the effects of (i) the increase in the replacement rate from $80 \%$ to $100 \%$ in $1999\left(\beta_{2}-\beta_{1}\right)$, the (ii) exclusion of overtime for Group II in $1997\left(\beta_{3}\right)$ and Group III and $1999\left(\beta_{3}-\beta_{4}\right)$, as well as (iii) the overall development of the sick leave rates from 1999 to 2004-when the system as a whole was more restrictive-relative to 1994 to $1996\left(\beta_{2} ; \beta_{4}\right)$.

One can summarize the following from Table 2 First, during the time when sick pay was cut to $80 \%$, in 1997 and 1998, we find overall decreases in the sickness rate by about $22 \%\left(\beta_{1}\right.$ in column (1)). This reflects $\hat{\beta}_{\tau}$ in equation $(14)$, i.e., the total moral hazard effect. As seen, $\beta_{1}$ is highly significant and clearly larger than zero, which confirms Proposition 4a. Related to the decrease in sick pay of $20 \%$, one obtains a sickness rate elasticity with respect to the replacement rate of about 1 . Decreases of similar size are found for respiratory and digestive diseases (columns (3) and (4)). 
Table 2: Effect of Changes in Sick Pay on Normalized Cases of Sick Leave by Disease Groups

\begin{tabular}{|c|c|c|c|c|c|c|}
\hline & $\begin{array}{l}\text { All } \\
\text { diseases }\end{array}$ & $\begin{array}{l}\text { Infectious } \\
(2)\end{array}$ & $\begin{array}{l}\text { Respiratory } \\
\text { (3) }\end{array}$ & $\begin{array}{l}\text { Digestive } \\
\text { (4) }\end{array}$ & $\begin{array}{l}\text { Musculosk. } \\
\text { (5) }\end{array}$ & $\begin{array}{l}\text { Inj. \& Pois. } \\
\text { (6) }\end{array}$ \\
\hline & \multicolumn{6}{|l|}{ (1) } \\
\hline $\begin{array}{l}\text { Group I×'97-'98 } \\
\text { (Effect of Cut'97) }\end{array}$ & $\begin{array}{l}-0.220^{* * *} \\
(0.057)\end{array}$ & $\begin{array}{l}-0.148^{* * *} \\
(0.047)\end{array}$ & $\begin{array}{l}-0.208^{* * *} \\
(0.054)\end{array}$ & $\begin{array}{l}-0.198^{* * *} \\
(0.056)\end{array}$ & $\begin{array}{l}-0.341^{* * *} \\
(0.076)\end{array}$ & $\begin{array}{l}-0.112^{* *} \\
(0.045)\end{array}$ \\
\hline $\begin{array}{l}\text { Group I×'99-'04 } \\
\text { (Level post-'99 vs. pre-'97) }\end{array}$ & $\begin{array}{l}-0.135^{*} \\
(0.070)\end{array}$ & $\begin{array}{l}-0.075 \\
(0.053)\end{array}$ & $\begin{array}{l}-0.131^{* * *} \\
(0.044)\end{array}$ & $\begin{array}{l}-0.098 \\
(0.057)\end{array}$ & $\begin{array}{l}-0.150 \\
(0.157)\end{array}$ & $\begin{array}{l}0.030 \\
(0.087)\end{array}$ \\
\hline $\begin{array}{l}\text { Group II } \times{ }^{\prime} 97-' 98 \\
\text { (Effect of Soft Cut '97) }\end{array}$ & $\begin{array}{l}-0.029 \\
(0.065)\end{array}$ & $\begin{array}{l}-0.041 \\
(0.073)\end{array}$ & $\begin{array}{l}-0.022 \\
(0.061)\end{array}$ & $\begin{array}{l}-0.048 \\
(0.062)\end{array}$ & $\begin{array}{l}-0.038 \\
(0.086)\end{array}$ & $\begin{array}{l}-0.006 \\
(0.065)\end{array}$ \\
\hline $\begin{array}{l}\text { Group II ×'99-'04 } \\
\text { (Level post-'99 vs. pre-'97) }\end{array}$ & $\begin{array}{l}0.053 \\
(0.078)\end{array}$ & $\begin{array}{l}0.053 \\
(0.070)\end{array}$ & $\begin{array}{l}0.017 \\
(0.055)\end{array}$ & $\begin{array}{l}0.000 \\
(0.066)\end{array}$ & $\begin{array}{l}0.131 \\
(0.164)\end{array}$ & $\begin{array}{l}0.107 \\
(0.095)\end{array}$ \\
\hline $\begin{array}{l}\left.\left.\text { [Group I } \times^{\prime} 99-^{\prime} 04\right] \text { - [Group I } \times^{\prime} 97-98\right] \\
\text { pvalue } \\
(\text { Effect of Increase '99) }\end{array}$ & $\begin{array}{l}0.084^{* * *} \\
0.000\end{array}$ & $\begin{array}{l}0.073 \\
0.121\end{array}$ & $\begin{array}{l}0.077^{* * *} \\
0.000\end{array}$ & $\begin{array}{l}0.100^{* * *} \\
0.000\end{array}$ & $\begin{array}{l}0.191^{* *} \\
0.032\end{array}$ & $\begin{array}{l}0.142^{* * *} \\
0.004\end{array}$ \\
\hline $\begin{array}{l}\text { R2 } \\
\text { Observations } \\
\text { Number of industries }\end{array}$ & $\begin{array}{l}0.659 \\
198 \\
18\end{array}$ & $\begin{array}{l}0.949 \\
198 \\
18\end{array}$ & $\begin{array}{l}0.816 \\
198 \\
18\end{array}$ & $\begin{array}{l}0.826 \\
198 \\
18\end{array}$ & $\begin{array}{l}0.858 \\
198 \\
18\end{array}$ & $\begin{array}{l}0.918 \\
198 \\
18\end{array}$ \\
\hline \multicolumn{7}{|c|}{$\begin{array}{l}\text { Source: (Bundesverbank der Betriebskrankenkassen (BKK), } 2004), \text { own calculation and illustration; }{ }^{*} \mathrm{p}<0.1,{ }^{* *} \mathrm{p}<0.05,{ }^{* * *} \mathrm{p}<0.01 ; \text { standard errors in } \\
\text { parentheses are clustered at the industry-level. All regressions are weighted by the annual number of industry-specific sickness fund enrollees. The } \\
\text { descriptive statistics are in the Appendix (Table A1). Each column represents one model as in equation }(15), \text { estimated by OLS, i.e., all models include } \\
\text { industry and year fixed effects. The dependent variables are logarithms of the normalized sick leave cases per } 100 \text { insurees. Column (1) employs the total } \\
\text { number of sick leave cases as dependent variable, column (2) solely uses certified infectious sick leave cases and so on. For more information on how the } \\
\text { variables were generated, see Section 4.2. Treated is a treatment indicator with one for Group I and zero for Group III, whereas PartlyTreated is one for } \\
\text { Group II and zero for Group III. Group I experienced a sick pay cut from } 100 \text { to } 80 \% \text { in } 1997 \text { and a reversal in } 1999 \text {. Group II experienced a soft cut in } \\
1997 \text { and Group III experienced a soft cut in 1999. For more information about the sick pay reforms, see Table } 1 \text {. }\end{array}$} \\
\hline
\end{tabular}


Second, musculoskeletal diseases is the category that represents best the non-contagious disease category $n$ in our model in Section 2. As a result of the sick pay cut, the sick leave rate of musculoskeletal diseases decreased overproportionally by $34 \%$ (column (5), $\left.\beta_{1}\right)$. The overproportional decrease for musculoskeletal diseases, which is composed of $70 \%$ back pain cases, fits the common perception that the labor supply of this category is particularly elastic and prone to shirking behavior. Equation (9) of our model illustrates the analytical derivation of $\beta_{n \tau}$. $\beta_{n \tau}$, which is represented by $\beta_{1}$ in column (5) of Table 2, equals the decrease in shirking as sick pay decreases.

Third, infectious diseases, ICD-10 codes A00-B99, is the category that best represents best the contagious disease category ${ }_{c}$ in our model. This estimate represents the $\beta_{c \tau}$ in our model in equation (11). As $\beta_{1}$ in column (2) of Table 2 shows, the infectious disease rate fell under proportionally by an estimated $15 \%$ as a response to the sick pay cut in 1997/1998. Note that this estimate is likely to be upward biased, since the pre-1997 common time trend for infectious diseases is not $100 \%$ clean as Figure $3 \mathrm{~d}$ nicely illustrates: While there is strong convincing support for an overall common time trend among all three groups and over the 11 year time period from 1994 to 2004, the only outlier is the pre-reform years 1994/1995, where we observe an above-trend increase among Group I. Considering this and assessing the overall infectious disease trend picture in Figure $3 \mathrm{~d}$, the estimated decrease of 15\% appears upwardly biased and the true estimate seems to tend more towards zero. In any case, while the findings suggest that $\beta_{n \tau}>\beta_{c \tau}$ as formulated in Hypothesis 1 and Proposition $4 c$, it is also clear that $\hat{\beta}_{\tau}>0$ holds, meaning that the reform led to a decrease in overall sickness absence.

Testing the Robustness of the Identified Effects. Table 2 also provides a series of additional estimates that allow us to check the plausibility and consistency of the identified model parameters $\hat{\beta}_{\tau}, \hat{\beta}_{n \tau}$, and $\hat{\beta}_{c \tau}$.

First of all, the reaction of sick leave due to injuries \& poisoning in column (6) of Table 2 serves as a robustness test since $50 \%$ of all injuries \& poisoning absences are due to workplace accidents (Bundesverbank der Betriebskrankenkassen (BKK), 2004). The first bill that cut sick pay, however, excluded sick leave due to workplace accidents from the cuts 
(see Section 3.2). Indeed, as see by $\beta_{1}$ in column (6), the injuries \& poisoning absence rate decreased underproportionally by almost exactly half the rate than the overall rate, namely by $11.2 \%$ instead of $22 \%$.

Second, the $\beta_{2}$ estimate provides the change in sickness rates in the post-1999 era relative to the pre-1997 era for Group I. Meanwhile, the F-test, $\beta_{2}-\beta_{1}=0$, yields the effect of an increase in the replacement rate to $100 \%$ in 1999 . Thus $\beta_{2}$ reflects the long-term impact after a series of reforms that made the overall system more restrictive and shows a decrease of $13.5 \%$ at the 10 percent significance level for all diseases. The same is true for respiratory diseases, while the coefficients are relatively large but not statistically significant for infectious $(-7.5 \%)$, digestive $(-9.8 \%)$, and musculoskeletal $(-15.0 \%)$ diseases. $\beta_{2}-\beta_{1}$ is highly significant for all disease categories but infectious diseases. Column (1) suggests that the overall rate increased again by $8.4 \%$ after the reversal. Column (5) also confirms our findings above and strongly suggests that musculoskeletal diseases, i.e. the group respresenting non-contagious diseases in the model, reacted overproportionally with an increase of $19.1 \%$ as a reaction to the increase in sick pay to $100 \%$.

Third, all separate $\beta_{3}$ and $\beta_{4}$ estimates are imprecise and relatively small in size meaning that-in an regression framework that employs industry and year fixed effects-we are unable to detect significant sick leave rate changes in response to the mild sick leave cuts that excluded overtime from the basis of calculation. However, this is at least partly a function of the statistical power that our data offer. Note that all coefficients carry the expected sign and most magnitudes lie around 3 to $5 \%$ In addition, when formally carrying out an F-test of $\beta_{3}-\beta_{4}=0$ to test the effect of the overtime exclusion in 1999 for Group III, we obtain enough precision and significant decreases in the sick leave rates. Also note that, while power can be an issue when it comes to the identification of small changes, as the R-squared in Table 2 indicates, our models are able to explain between $66 \%$ and $95 \%$ of the variation in sick leave rates over time and between industries.

\footnotetext{
${ }^{30}$ Remember that we likely overestimate the behavioral reactions for infections due to a deviation from the common time trend pre-1997, as discussed above and shown in Figure $3 \mathrm{~d}$.

${ }^{31}$ Recall again that the 1999 exclusion of overtime was effective for Group III but not for Group II while the opposite was true when the first reform was implemented. This means that the positive signs of $\beta_{4}$ actually represent decreases in the sick leave rate as a result of the overtime exclusion.
} 
In conclusion, all findings strongly confirm the robustness of our results for $\hat{\beta}_{\tau}, \hat{\beta}_{n \tau}$, and $\hat{\beta}_{c \tau}$ above. Moreover, they are entirely in line with the graphical evidence (see Figure 3 ) as well as our discussion above: overall sickness rates in the Group I clearly increased again after the sick pay cut was reversed. However, the increase kicked-in with a lag of about one year and we observe time persistence in the behavioral reactions-the reform-induced sick pay gaps among the three groups did not entirely close until the end of the observation period. Finally, the labor supply elasticities are smallest for infectious diseases and largest for musculoskeletal diseases. The former category represents non-contagious and the latter non-contagious diseases.

\section{Does the Decrease in Shirking Outweigh the Negative Externalities of Contagious Pre- senteeism?}

Estimating $\beta_{n \tau}-\beta_{c \tau}$. Next, we pool the different disease-industry-year observations and run regression models as in equation (16). Following Proposition $4 \mathbf{c}$, this allows us to directly carry out the following statistical tests $\beta_{n \tau}=\beta_{c \tau}$.

Column (1) of Table 3 simply replicates column (5) of Table 2 and carries 198 observations. Column (5) of Table 2 estimated the impact on musculoskeletal diseases, our main reference group for non-contagious diseases.

Column (2) adds our main contagious disease category infectious diseases and has 396 observations. With musculoskeletal diseases as the baseline category, the four triple DiD interaction terms (i) Group $I_{i} \times{ }^{\prime} 97-^{\prime} 98 \times$ Infectious, (ii) Group $I_{i} \times{ }^{\prime} 99-^{\prime} 04 \times$ Infectious, (iii) GroupII $I_{i} \times 97-{ }^{\prime} 98 \times$ Infectious, and (iv) GroupI $I_{i} \times{ }^{\prime} 99-^{\prime} 04 \times$ Infectious - or $\gamma_{i 1}-\gamma_{i 5}$ directly test Hypothesis $\mathbf{1}\left(\beta_{n \tau}=\beta_{c \tau}\right)$. What has already been suggested in Table 2 above, can now be demonstrated with statistical certainty in column (2) of Table 3: $\hat{\beta}_{c \tau}-\hat{\beta}_{n \tau}=19.3$ percentage points, meaning that the sick pay cut induced decrease in the contagious sick leave rate was a significant 19.3 percentage points smaller than the decrease in the noncontagious sick leave rate (14.8\% vs. $34.1 \%$, see columns (2) and (5) of Table 2). Again, this is likely an underestimate since we likely overestimate $\beta_{c \tau}$. 
Table 3: Effect of Changes in Sick Pay on Normalized Cases of Sick Leave: Pooled Regressions

\begin{tabular}{|c|c|c|c|}
\hline & $\begin{array}{c}\text { (1) } \\
\text { Musculoskeletal }\end{array}$ & $\begin{array}{c}(2) \\
\text { Musculoskeletal, } \\
\text { Infectious }\end{array}$ & $\begin{array}{c}\text { (3) } \\
\text { Muscul., Infect. } \\
\text { Respiratory }\end{array}$ \\
\hline Group I×'97-'98 & $\begin{array}{l}-0.341^{* * *} \\
(0.076)\end{array}$ & $\begin{array}{c}-0.341^{* * *} \\
(0.075)\end{array}$ & $\begin{array}{c}-0.341^{* * *} \\
(0.075)\end{array}$ \\
\hline Group I×'99-'04 & $\begin{array}{l}-0.150 \\
(0.157)\end{array}$ & $\begin{array}{l}-0.150 \\
(0.155)\end{array}$ & $\begin{array}{l}-0.150 \\
(0.154)\end{array}$ \\
\hline Group II×'97-'98 & $\begin{array}{l}-0.038 \\
(0.086)\end{array}$ & $\begin{array}{l}-0.038 \\
(0.085)\end{array}$ & $\begin{array}{l}-0.038 \\
(0.085)\end{array}$ \\
\hline Group II×'99-'04 & $\begin{array}{c}0.131 \\
(0.164)\end{array}$ & $\begin{array}{c}0.131 \\
(0.161)\end{array}$ & $\begin{array}{c}0.131 \\
(0.161)\end{array}$ \\
\hline Group I×'97-'98× Infectious & & $\begin{array}{l}0.193^{* *} \\
(0.088)\end{array}$ & $\begin{array}{l}0.193^{* *} \\
(0.088)\end{array}$ \\
\hline Group I×'99-'04×Infectious & & $\begin{array}{c}0.075 \\
(0.164)\end{array}$ & $\begin{array}{c}0.075 \\
(0.163)\end{array}$ \\
\hline Group II ×'97-'98× Infectious & & $\begin{array}{l}-0.003 \\
(0.112)\end{array}$ & $\begin{array}{l}-0.003 \\
(0.111)\end{array}$ \\
\hline Group II ×'99-'04× Infectious & & $\begin{array}{l}-0.079 \\
(0.176)\end{array}$ & $\begin{array}{c}-0.079 \\
(0.175)\end{array}$ \\
\hline Group I×'97-'98× Respiratory & & & $\begin{array}{c}0.133 \\
(0.092)\end{array}$ \\
\hline Group I×'99-'04× Respiratory & & & $\begin{array}{c}0.019 \\
(0.160)\end{array}$ \\
\hline Group II×'97-'98× Respiratory & & & $\begin{array}{l}0.016 \\
(0.104)\end{array}$ \\
\hline Group II×'99-'04× Respiratory & & & $\begin{array}{l}-0.115 \\
(0.170)\end{array}$ \\
\hline Observations & 198 & 396 & 594 \\
\hline $\mathrm{R} 2$ & 0.858 & 0.982 & 0.989 \\
\hline \multicolumn{4}{|c|}{$\begin{array}{l}\text { Source: }(\text { Bundesverbank der Betriebskrankenkassen (BKK), } 2004,, \text { own calculation and illustration; } \\
{ }^{*} \mathrm{p}<0.1,{ }^{* *} \mathrm{p}<0.05,{ }^{* * *} \mathrm{p}<0.01 \text {; standard errors in parentheses are clustered at the industry-disease- } \\
\text { level. All regressions are weighted by the annual number of industry-specific sickness fund enrollees. } \\
\text { The descriptive statistics are in the Appendix (Table A1). The regressions are based on equation } 16 \text {. } \\
\text { The model in the first column equals the fifth column of Table 2. The model in the second column } \\
\text { pools the two categories muscoloskeletal and infectious, where muscoloskeletal form the reference } \\
\text { group. The third column additionally adds respiratory diseases. The fourth column adds all other } \\
\text { diseases as a separate category. All regressions are estimated by OLS and include industry, disease } \\
\text { and year fixed effects. The dependent variables are logarithms of the normalized sick leave cases per } \\
100 \text { insurees. For more information on how the variables were generated, see Section } 4.2 \text { Treated is } \\
\text { a treatment indicator with one for Group I and zero for Group III, whereas PartlyTreated is one for } \\
\text { Group II and zero for Group III. Group I experienced a sick pay cut from } 100 \text { to } 80 \% \text { in } 1997 \text { and } \\
\text { a reversal in } 1999 \text {. Group II experienced a soft cut in } 1997 \text { and Group III experienced a soft cut in } \\
\text { 1999. For more information about the sick pay reforms, see Table } 1 \text {. }\end{array}$} \\
\hline
\end{tabular}

Although not statistically significant due to the statistical power of our data, our estimates are relatively large and carry the expected sign. $\gamma_{I 2}$ yields the long-term difference in 
the adjustment rate for musculoskeletal vs. infectious diseases illustrating again that infectious sick leave rates are much less responsive, also in the long-run. The triple DiD estimate $\gamma_{\text {I4 }}$ shows the long-term effect post-1999 vs. pre-1997 for Group II as compared to Group III and musculoskeletal vs. infectious diseases. The visual equivalent to $\gamma_{I 2}$ and $\gamma_{I 4}$ is to compare the post-1999 sickness rate gaps for musculoskeletal vs. infectious diseases relative to the pre-1997 gaps in Figures 3b vs. 3d. Figures 3b and 3d illustrate very nicely and even more clearly than Table 3 that there was basically no behavioral reaction for infectious diseases while one observes substantial behavioral reactions for musculoskeletal diseases.

Finally, column (3) serves as yet another robustness check and additionally adds respiratory diseases to the data set. While not all respiratory diseases are contagious, this category contains "influenza (J09)", commonly referred to as the flu. As above, the four triple interaction terms identify the differential effect relative to the baseline category musculoskeletal diseases. Again, although we lack statistical power, there is suggestive evidence that the respiratory sick leave rate decreased by about $13 \%$ less than the non-contagious baseline $\left(\gamma_{R 1}\right)$. Similarly, the impact of the soft cut for Group III seems to have been less strong $\left(\gamma_{R 3}-\gamma_{R 4}\right)$.

\section{Conclusion}

Empirically identifying presenteeism behavior is extremely challenging, yet crucial in order to test for one major economic justification for publicly provided sick pay: that being the negative externalities associated with contagious presenteeism. Contagious presenteeism refers to the phenomenon when employees with infectious diseases go to work sick and infect co-workers and customers. Such behavior is a major public health issue and one driving force of the spread of contagious diseases. If contagion is unobservable, which is unusually the case at the beginning of a sickness episode, then state regulation may reduce market inefficiencies by providing monetary incentives to stay home when sick. If such monetary incentives work, and economic theory as well empirical studies strongly suggest that they do, then public sick pay schemes reduce contagious presenteeism and the spread of diseases. 
To our knowledge, this study is the first that theoretically derives and empirically implements tests for the existence of contagious presenteeism and negative externalities in sickness insurance schemes. First, our model theoretically defines different possible cases of workplace absence behavior under contagious and non-contagious continuous sickness levels. As such, we also decompose classical moral hazard into (i) shirking behavior, and (ii) contagious presenteeism. Case (i) does not imply negative health spillovers, whereas case (ii) does. We derive conditions to be able to test for moral hazard and its decomposed elements (i) and (ii). Then, we exploit two German sick pay reforms and administrative physician-certified sick leave data at the industry-level to provide empirical evidence for the existence of contagious presenteeism, which we indeed find. However, we also show that, in Germany, with one of the most generous sick leave systems worldwide, the reduction in shirking behavior was larger than the increase in the infectious disease rate due to contagious presenteeism when sick pay was cut from a baseline level of $100 \%$.

Our proposed method can be applied to different settings in order to test for the existence and the degree of contagious presenteeism, shirking behavior, and the overall level of moral hazard. Important fields of applications include (a) contagious presenteeism by teachers or school kids, e.g., induced by the (non-)generosity of teacher or parental sick pay schemes that may or may not cover sickness of children. Another relevant application would be to test for $(b)$ contagious presenteeism behavior by service sector employees with a high degree of customer contact, e.g., induced by the (non-)generosity of a firm-level sick pay scheme. As a last example, (c) contagious presenteeism behavior by health care workers can be lifethreatening for patients, but potentially be minimized by optimized sick pay schemes. Note that our test can be carried out using many different types of data, including school-level, firm-level data, or hospital-level data.

More research is needed in order to better understand how exactly contagious presenteeism leads to infections of co-workers and customers and affect overall workplace productivity. Firm-level and employee-level compensation strategies to dampen sickness-related productivity losses are also fruitful related research questions. 


\section{References}

Arnott, R. and J. Stiglitz (1991). The welfare economics of moral hazard. In H. Louberg (Ed.), Risk, Information and Insurance, pp. 91-121. Springer Netherlands.

Aronsson, G., K. Gustafsson, and M. Dallner (2000). Sick but yet at work. An empirical study of sickness presenteeism. Journal of Epidemiology E Community Health 54(7), 502-509.

Askildsen, J. E., E. Bratberg, and Ø. A. Nilsen (2005). Unemployment, labor force composition and sickness absence: A panel study. Health Economics 14(11), 1087-1101.

Barmby, T. and M. Larguem (2009). Coughs and sneezes spread diseases: An empirical study of absenteeism and infectious illness. Journal of Health Economics 28(5), 1012-1017.

Barmby, T., J. Sessions, and J. G. Treble (1994). Absenteeism, efficiency wages and shirking. Scandinavian Journal of Economics 96(4), 561-566.

Bhattacharya, J. and M. Packalen (2012). The other ex ante moral hazard in health. Journal of Health Economics 31(1), 135-146.

Blank, P. R., M. M. Schwenkglenks, and T. D. Szucs (2009). Vaccination coverage rates in eleven European countries during two consecutive influenza seasons. Journal of Infection 58(6), 446-458.

Blien, U., E. J. Jahn, G. Stephan, M. Knig, and J. Mller (2009). Impacts of minimum wages: a microdata analysis for the german construction sector. International Journal of Manpower 30(7), 716-741.

Boots, S. W., K. Martinson, and A. Danziger (2009). Employers' perspectives on San Francisco's paid sick leave policy. Technical report, The Urban Institute. http://www . urban.org/publications/411868.html, last accessed on April 5, 2012.

Brown, S. (1994). Dynamic implications of absence behaviour. Applied Economics 26, 11631175.

Brown, S. and J. G. Sessions (1996). The economics of absence: Theory and evidence. Journal of Economic Surveys 10(1), 23-53.

Brown, S. and J. G. Sessions (2004). Absenteeism, presenteeism, and shirking. Economic Issues 9(1), 15-23.

Bruine de Bruin, W., A. Parker, and J. Maurer (2011). Assessing small non-zero perceptions of chance: The case of H1N1 (swine) flu risks. Journal of Risk and Uncertainty 42(2), 145-159.

Bundesverbank der Betriebskrankenkassen (BKK) (1994-2004). Krankheitsartenstatistik. BKK Bundesverband.

Busse, R. and A. Riesberg (2004). Health care systems in transition: Germany (1 ed.). WHO Regional Office for Europe on behalf of the European Observatory on Health Systems and Policies. 
Centers for Disease Control and Prevention (2014a). Final state-level influenza vaccination coverage estimates for the 2010-11 season - United States, National Immunization Survey and Behavioral Risk Factor Surveillance System, August 2010 through May 2011. CDC. http: //www.cdc.gov/flu/fluvaxview/coverage_1011estimates.htm, last accessed on June 19, 2014.

Centers for Disease Control and Prevention (2014b). Seasonal Influenza (Flu). CDC. http:// Www. cdc.gov/flu/about/di sease/index.htm, last accessed on September 9, 2014.

Chatterji, M. and C. J. Tilley (2002). Sickness, absenteeism, presenteeism, and sick pay. $O x$ ford Economic Papers 54, 669-687.

Dale-Olsen, H. (2013). Absenteeism, efficiency wages, and marginal taxes. Scandinavian Journal of Economics 115(4), 1158-1185.

Dale-Olsen, H. (2014). Sickness absence, sick leave pay, and pay schemes. Labour 28(1), 40-63.

De Paola, M., V. Scoppa, and V. Pupo (2014). Absenteeism in the Italian public sector: The effects of changes in sick leave policy. Journal of Labor Economics 32(2), 337-360.

Earn, D. J. D., P. W. Andrews, and B. M. Bolker (2014). Population-level effects of suppressing fever. Proceedings of the Royal Society B: Biological Sciences 281(1778).

Eibich, P., H. Schmitz, and N. R. Ziebarth (2012). Add-on premiums increase price transparency: More policy holders switch health plans. DIW Economic Bulletin 2(2), 15-24.

Einav, L., A. Finkelstein, S. P. Ryan, P. Schrimpf, and M. R. Cullen (2013). Selection on moral hazard in health insurance. The American Economic Review 103(1), 178-219.

Felder, S. (2008). To wait or to pay for medical treatment? restraining ex-post moral hazard in health insurance. Journal of Health Economics 27(6), 1418-1422.

Fevang, E., S. Markussen, and K. Røed (2014). The sick pay trap. Journal of Labor Economics 32(2), 305-336.

German Federal Statistical Office (1998). Statistical Yearbook 1998 for the Federal Republic of Germany. Metzler-Poeschel.

German Federal Statistical Office (2014). Federal Health Monitoring. www . gbe-bund . de, last accessed on October 25, 2014.

Gruber, J. (1994). The incidence of mandated maternity benefits. American Economic Review 84(3), 622-641.

Hans Böckler Stiftung (2014). WSI Tarifarchiv. Deutscher Gewerkschaftsbund (DGB). http: //www.boeckler.de/index_wsi_tarifarchiv.htm, last accessed on June 19, 2014.

Heymann, J., H. J. Rho, J. Schmitt, and A. Earle (2009). Contagion nation: a comparison of paid sick day policies in 22 countries. Technical Report 2009-19, Center for Economic and Policy Research (CEPR). http://www. cepr.net/documents/publications/ paid-sick-days-2009-05.pdf, last accessed on April 5, 2012. 
Ichino, A. and G. Maggi (2000). Work environment and individual background: Explaining regional shirking differentials in a large Italian firm. The Quarterly Journal of Economics 115(3), 1057-1090.

Ichino, A. and E. Moretti (2009). Biological gender differences, absenteeism, and the earnings gap. American Economic Journal: Applied Economics 1(1), 183-218.

Ichino, A. and R. T. Riphahn (2005). The effect of employment protection on worker effort. A comparison of absenteeism during and after probation. Journal of the European Economic Association 3(1), 120-143.

Jahn, J. (1998). Lohnfortzahlung: Gerichte stehen vor Herkulesaufgabe. Handelsblatt July, 2, 4.

Johansson, P. and M. Palme (1996). Do economic incentives affect work absence? Empirical evidence using Swedish micro data. Journal of Public Economics 59(1), 195-218.

Johansson, P. and M. Palme (2002). Assessing the effect of public policy on worker absenteeism. Journal of Human Resources 37(2), 381-409.

Johansson, P. and M. Palme (2005). Moral hazard and sickness insurance. Journal of Public Economics 89(9-10), 1879-1890.

Karlsson, M., T. Nilsson, and S. Pichler (2014). The impact of the 1918 Spanish flu epidemic on economic performance in Sweden. Journal of Health Economics 36(0), 1-19.

Kermack, W. and A. McKendrick (1927). A contribution to the mathematical theory of epidemics. Proceedings of the Royal Society of London. Series A 115(772), 700-721.

Lovell, V. (2003). No time to be sick: Why everyone suffers when workers don't have paid sick leave. Policy report, Institute for Womens Policy Research. http://www.iwpr. org/publications/pubs/, last accessed at March 19, 2014.

Markussen, S. (2012). The individual cost of sick leave. Journal of Population Economics 25(4), 1287-1306.

Markussen, S., A. Mykletun, and K. Røed (2012). The case for presenteeism: Evidence from Norway's sickness insurance program. Journal of Public Economics 96(11), 959-972.

Markussen, S., K. Røed, O. J. Røgeberg, and S. Gaure (2011). The anatomy of absenteeism. Journal of Health Economics 30(2), 277-292.

Maurer, J. (2009). Who has a clue to preventing the flu? Unravelling supply and demand effects on the take-up of influenza vaccinations. Journal of Health Economics 28(3), 704-717.

Medizinischer Dienst der Krankenversicherung (MDK) (2014). www . mdk . de, last accessed at April 27, 2014.

Mullahy, J. (1999). It'll only hurt a second? Microeconomic determinants of who gets flu shots. Health Economics 8(1), 9-24.

Newhouse, J. P. (2006). Reconsidering the moral hazard-risk avoidance tradeoff. Journal of Health Economics 25(5), 1005-1014. 
Nordberg, M. and K. Røed (2009). Economic incentives, business cycles, and long-term sickness absence. Industrial Relations 48(2), 203-230.

Nyman, J. A. (1999). The economics of moral hazard revisited. Journal of Health Economics 18(6), 811-824.

Pauly, M. (1983). More on moral hazard. Journal of Health Economics 2(1), 81-85.

Pauly, M. V. (1974). Overinsurance and public provision of insurance: The roles of moral hazard and adverse selection. The Quarterly Journal of Economics 88(1), 44-62.

Pauly, M. V., S. Nicholson, D. Polsky, M. L. Berger, and C. Sharda (2008). Valuing reductions in on-the-job illness: 'presenteeism' from managerial and economic perspectives. Health Economics 17(4), 469-485.

Philipson, T. (2000). Economic epidemiology and infectious diseases. In A. J. Culyer and J. P. Newhouse (Eds.), Handbook of Health Economics, Volume 1 of Handbook of Health Economics, Chapter 33, pp. 1761-1799. Elsevier.

Pichler, S. (2014). Sickness absence, moral hazard, and the business cycle. Health Economics. forthcoming.

Puhani, P. A. and K. Sonderhof (2010). The effects of a sick pay reform on absence and on health-related outcomes. The Journal of Health Economics 29(2), 285-302.

Rattenhuber, P. (2011). Building the minimum wage: Germany's first sectoral minimum wage and its impact on wages in the construction industry. Discussion papers, German Institute for Economic Research (DIW Berlin) 1111.

Ridinger, R. (1997). Einfluss arbeitsrechtlicher Regelungen auf die Beschäftigungsentwicklung im Handwerk-Ergebnisse von Befragungen von Handwerksbetrieben im 3. Quartal 1997. Technical report, Zentralverband des Deutschen Handwerks. http: // www. zdh. de, last accessed on June 19, 2009.

Riphahn, R. T. (2004). Employment protection and effort among German employees. Economics Letters 85, 353-357.

Ross, R. (1916). An application of the theory of probabilities to the study of a priori pathometry. Part I. Proceedings of the Royal Society of London. Series A 92(638), 204-230.

Rossin-Slater, M., C. J. Ruhm, and J. Waldfogel (2013). The effects of California's Paid Family Leave Program on mothers leave? taking and subsequent labor market outcomes. Journal of Policy Analysis and Management 32(2), 224-245.

Ruhm, C. J. (1998). The economic consequences of parental leave mandates: Lessons from Europe. The Quarterly Journal of Economics 113(1), 285-317.

Sandy, R. and R. F. Elliott (2005). Long-term illness and wages: The impact of the risk of occupationally related long-term illness on earnings. Journal of Human Resources 40(3), 744-768.

Schmitz, H. and N. R. Ziebarth (2013). How framing prices affects the consumer price sensitivity of health plan choice. mimeo, Cornell University. http: / /www . human . cornell. edu/pam/people/nicolas_ziebarth. cfm, last accessed on December 15, 2013. 
Scoppa, V. and D. Vuri (2014). Absenteeism, unemployment and employment protection legislation: evidence from Italy. IZA Journal of Labor Economics 3(1), 1-25.

SOEPGroup (2008). German Socio-economic Panel Study (SOEP), data of the years 19842007. DOI: $10.5684 /$ soep.v24.

Thomas, M. (2015). The impact of mandated maternity benefits on the gender differential in promotions: Examining the role of adverse selection. Technical report. mimeo.

Uscher-Pines, L., J. Maurer, and K. M. Harris (2011). Racial and ethnic disparities in uptake and location of vaccination for 2009-H1N1 and seasonal influenza. American Journal of Public Health 101(7), 1252-1255.

Waldfogel, J. (1998). Understanding the "family gap" in pay for women with children. Journal of Economic Perspectives 12(1), 137-156.

World Health Organization (2014). Influenza (Seasonal). WHO. http://www.who.int/ mediacentre/factsheets/fs211/en/, last accessed on June 19, 2014.

Ziebarth, N. R. (2013). Long-term absenteeism and moral hazard-Evidence from a natural experiment. Labour Economics 24, 277292.

Ziebarth, N. R. and M. Karlsson (2010). A natural experiment on sick pay cuts, sickness absence, and labor costs. Journal of Public Economics 94(11-12), 1108-1122.

Ziebarth, N. R. and M. Karlsson (2014). The effects of expanding the generosity of the statutory sickness insurance system. Journal of Applied Econometrics 29(2), 208-230. 


\section{Appendix}

Table A1: Descriptive Statistics of Sick Leave Measures

\begin{tabular}{|c|c|c|c|c|c|}
\hline Variable & Mean & Std. Dev. & Min. & Max. & $\mathbf{N}$ \\
\hline Total sick cases per 100 enrollees & 122.2711 & 11.521 & 90.2686 & 162.8341 & 198 \\
\hline Total $\log ($ cases $)$ & 4.8017 & 0.0959 & 4.5028 & 5.0927 & 198 \\
\hline Infectious sick cases per 100 enrollees & 8.2072 & 2.2201 & 3.8964 & 14.8765 & 198 \\
\hline Infectious $\log ($ hcases $)$ & 2.0658 & 0.2866 & 1.36 & 2.6998 & 198 \\
\hline Respiratory sick cases per 100 enrollees & 35.4062 & 4.3171 & 25.1606 & 50.0485 & 198 \\
\hline Respiratory $\log ($ cases $)$ & 3.5593 & 0.1244 & 3.2253 & 3.913 & 198 \\
\hline Digestive sick cases per 100 enrollees & 16.2847 & 2.0084 & 12.8124 & 24.0492 & 198 \\
\hline Digestive $\log ($ hcases $)$ & 2.783 & 0.1198 & 2.5504 & 3.1801 & 198 \\
\hline Musculoskeletal sick cases per 100 enrollees & 22.7377 & 4.9248 & 9.7523 & 34.3787 & 198 \\
\hline Musculoskeletal log(cases) & 3.0978 & 0.238 & 2.2775 & 3.5374 & 198 \\
\hline Injury sick cases per 100 enrollees & 12.7108 & 3.2117 & 6.8180 & 23.485 & 198 \\
\hline Injury $\log ($ hcases $)$ & 2.5113 & 0.2506 & 1.9196 & 3.1564 & 198 \\
\hline
\end{tabular}


Table A2: Number of Enrollees per Industry and Treatment Group

\begin{tabular}{lcc}
\hline \hline Industry and Classification & Mean & Std. Dev. \\
\hline Group I & & \\
\hline Construction & 127,642 & 104,205 \\
Group II & & \\
\hline Steel & 109,397 & 7,405 \\
Textile & 32,367 & 7,854 \\
Mechanical Engineering & 191,391 & 44,035 \\
Automobile & 301,725 & 43,313 \\
Ship and Aerospace & 33,626 & 9,323 \\
Electrical engineering, optics & 306,296 & 71,383 \\
Wood and Paper & 57,070 & 27,307 \\
Printing & 38,477 & 19,605 \\
Food and Hospitality & 55,045 & 33,748 \\
Trade & 341,566 & 227,279 \\
Banking and Insurance & 149,188 & 74,095 \\
& & \\
Group III & & \\
\hline Chemical & 230,382 & 46,215 \\
Oil & 15,586 & 5,074 \\
Glass & 34,097 & 5,480 \\
Energy and Water & 50,702 & 13,149 \\
Postal and Transportation & 478,490 & 104,031 \\
Public Administration & 732,958 & 476,804 \\
& & \\
\hline
\end{tabular}

Sources: (Bundesverbank der Betriebskrankenkassen (BKK), 2004), own calculation and illustration. 